\title{
Spatial Scaling of Land Use/Land Cover And Ecosystem Services Across Urban Hierarchical Levels: Patterns And Relationships
}

\section{Xiao Sun}

Chinese Academy of Agricultural Sciences

Qun Ma ( $\square$ maqun0127@shnu.edu.cn )

Shanghai Normal University

\section{Research Article}

Keywords: Ecosystem services, Land use/land cover, Scaling relations, Urban agglomeration, 44 Urban hierarchical levels

Posted Date: May 6th, 2021

DOI: https://doi.org/10.21203/rs.3.rs-425853/v1

License: (c) (i) This work is licensed under a Creative Commons Attribution 4.0 International License.

Read Full License

Version of Record: A version of this preprint was published at Landscape Ecology on January 31st, 2022. See the published version at https://doi.org/10.1007/s10980-021-01387-4. 


\section{Spatial scaling of land use/land cover and ecosystem services}

\section{2 across urban hierarchical levels: Patterns and relationships}

$5 \quad$ Xiao Sun

6 Key Laboratory of Agricultural Remote Sensing (AGRIRS), Ministry of Agriculture and Rural

7 Affairs/Institute of Agricultural Resources and Regional Planning, Chinese Academy of

8 Agricultural Sciences, Beijing 100081, China

9 Email: sunxiao@ caas.cn

11 Xiao Sun

12 State Key Laboratory of Urban and Regional Ecology, Research Center for Eco-Environmental

13 Sciences, Chinese Academy of Sciences, Beijing 100085, China

Qun $\mathrm{Ma}^{*}$

16 School of Environmental and Geographical Sciences, Shanghai Normal University, Shanghai

$17 \quad 200234$, China

18 Email: maqun0127@shnu.edu.cn 
Abstract

Context Land use/land cover (LULC) patterns seriously affect the ecosystem services (ESs), especially in highly developed urban agglomerations. Exploring how LULC and ESs change spatially across urban hierarchical levels and understanding the possible mechanisms can promote the sustainable planning of urban landscapes.

Objectives By mapping the spatial patterns of LULC and ESs in three largest urban agglomerations of China, this study aimed to (1) identify the scaling relations of LULC and ESs across different urban hierarchical levels, (2) explore the possible mechanisms of these two types of spatial scaling, and (3) explore how the scaling relations of ESs response to LULC and its policy implications.

Methods Based on LULC, we used the Integrated Valuation of Ecosystem Services and Tradeoffs (InVEST) model and other biophysical models to quantify ES indicators. Then, scalograms were used to quantify the scaling relations of LULC and ESs with respect to changing spatial extent.

Results Developed land and cropland exhibited the most predictable responses with changing spatial extent. Compared to other ESs, provisioning services were the most predictable. The predictable scaling relations of ESs at different urban hierarchical levels fell into two general types: power laws at the city proper level and exponential relationships at the metropolitan region and urban agglomeration levels.

Conclusions The scaling relations of both LULC and ESs varied across urban hierarchical levels. The spatial scaling of ESs was closely related to LULC patterns. Integrating the scaling relations of ESs into land use planning can help decision-makers formulate multi-scale landscape conservation strategies.

Keywords Ecosystem services $\cdot$ Land use/land cover $\cdot$ Scaling relations $\cdot$ Urban agglomeration · Urban hierarchical levels 


\section{Introduction}

For the past few decades, many parts of the world have been undergoing dramatic and rapid urbanization (Stokes and Seto, 2019). As the world's most populous country, China has also experienced dramatic urban expansion and socioeconomic development since the national reform and opening up policies of 1978 (Chen et al. 2020; Liu et al. 2020). Various studies have used population density (Normile 2016; Poku-Boansi 2021) or built-up land area (Seto et al. 2012; Xu et al. 2018) to represent or measure urbanization. The urbanization population rate in China increased from $17.9 \%$ in 1978 to $59.6 \%$ in 2018 (Wu et al. 2020), and the urban land area expanded from $21,770 \mathrm{~km}^{2}$ to $74,827 \mathrm{~km}^{2}$ in the same period (Kuang 2020a). This rapid urbanization has caused dramatic changes in land use/land cover (LULC) compositions and structures with high spatial heterogeneity (Hasan et al. 2020; Lawler et al. 2014). As the basis of assessing ESs, LULC changes have resulted in myriad impacts on natural resources and further threatening ESs from a local to global scale, such as with water scarcity (Li et al. 2020), climate change (Patra et al. 2018), soil erosion (Hu et al. 2019), and habitat loss (Swenson and Franklin 2000). Studying how LULC and ESs change spatially in rapidly urbanizing regions is important for better understanding and predicting the patterns and processes of urbanization across multiple scales, and the findings may further benefit urban sustainable planning and ecological protection (Batty 2008; Wu et al. 2011; Zhao et al. 2018b).

Previous studies have explored the spatial characteristics of LULC patterns and ESs (Hasan et al. 2020; Viglizzo et al. 2012). However, we still lack further information about the spatial scale effects of LULC and ESs, and their underlying mechanisms. The hierarchical scaling strategy provides an effective method of investigating spatial heterogeneity of complex urban systems over a range of scales (O'Neill et al. 1986; Wu 1999; Wu and David 2002). First, urban systems exhibit a hierarchically structured system wherein large urban regions consist of individual cities, which in turn consist of a smaller city proper (Ma et al. 2019). Thus, the hierarchical perspective can systematically characterize the impacts of landscape patterns on ecological processes in urban regions (Bian et al. 2020; Ma et al. 2016b; Zhang et al. 2020b). Second, the scaling approach is a powerful tool that can quantify multiscale characteristics explicitly and describe how various urban attributes scale with city size (Bettencourt 2013; Lobo et al. 2020).

Until now, the scaling approach has predominantly been used to focused on two themes: The first theme is how urban metrics (e.g., physical, demographic, economic, or environmental attributes) change within city sizes (usually represented by the population size or urban area) (Brock 1999; Fuller and Gaston 2009; Zhao et al. 2018a). Previous studies illustrated that most urban attributes follow approximate power law scaling, with different scaling exponents (e.g., $>1$ for certain quantities reflecting wealth creation and innovation and $<1$ for certain material infrastructural quantities) (Bettencourt et al. 2007; Bettencourt et al. 2010; Ribeiro et al. 2020). The second theme is how landscape patterns (e.g., landscape shape) or ecological processes (e.g., 
the relations between impervious surface area and land surface temperature) change with spatial scale (e.g., grain size or extent). For example, Wu (2004) systematically investigated the responses of landscape metrics to changing scale and classified the responses into two categories: simple scaling functions and unpredictable behavior. In general, most of the existing studies have focused on landscape patterns (Kedron et al. 2018; Wu et al. 2004; Zhang et al. 2009) but neglected to explore the scaling relations of ecological process and ES indicators. In the studies on landscape patterns, researchers rarely investigate the specific scaling relations for different LULC types. Especially, it is still unclear how the scaling relations of different LULC types and multiple ESs change in rapidly urbanized regions with a hierarchical structure.

Urban agglomeration is a highly developed spatial form of integrated cities and exhibits a hierarchically structured system (Ma et al. 2019; Wang et al. 2019b). As urban complex systems, urban agglomerations are suffering the most serious changes in terms of LULC and ESs (Shen et al. 2020; Yu et al. 2019; Zhou et al. 2018). Thus, we selected the top three urban agglomerations in China, the Beijing-Tianjin-Hebei (BTH), the Yangtze River Delta (YRD), and the Pearl River Delta (PRD) areas (Du et al. 2018), to explore the spatial features of LULC and ESs. The scaling evolutions of various LULC types and ESs can help to predict or speculate the indicator values, from one scale to another unknown scale (Xu et al. 2020). In addition, understanding the possible processes and mechanisms behind the scaling functions of urban metrics is helpful for guiding land use management and sustainable policy practice at different urban hierarchical levels globally.

This study used the hierarchical scaling strategy to investigate how different LULC types and ESs change within the spatial extent of the three largest urban agglomerations in China. We aimed to achieve the following research objectives: (1) analyze the scaling relations of LULC and ESs across different urban hierarchical levels; (2) understand the underlying mechanisms behind the scaling relations of LULC and ESs; and (3) explore how the scaling relations of ESs respond to LULC and its policy implications.

\section{Methods}

Study area

The top three urban agglomerations, BTH, YRD, and PRD (Fig. 1), cover only $5 \%$ of Chinese territory (DUSNB, 2019) but generate $40 \%$ of the total national urban impervious surface (Ma et al. 2019). They are the primary carriers of China's socioeconomic development and new urbanization processes (Fang and Yu 2017). In 2018, BTH, YRD, and PRD accounted for 8.1\%, $11.0 \%$, and $5.1 \%$ of the total national urban population and $9.5 \%, 16.7 \%$, and $9.2 \%$ of the total gross domestic product (GDP), respectively (DUSNB 2019). In addition to their importance to China's economic and social development, these three urban agglomerations constitute the typical and core regions of prominent environmental issues in China (Zhang et al. 2017; Gao et al. 2019). 
121 boundary for regional planning and policy implementation (Forgione et al. 2016; Nikodinoska et 122 al. 2018; Xing et al. 2021). BTH, YRD, and PRD consist of mature and complete nested urban 123 hierarchical levels that extend from the city proper, metropolitan region to the broader urban agglomeration (Ma et al. 2019). The lowest city proper level (the city proper of Beijing, Shanghai, or Guangzhou) belongs to a metropolitan region (Beijing, Shanghai, or Guangzhou metropolitan region), and is also embedded in the highest urban agglomeration level (BTH, YRD, or PRD urban agglomeration) (Fig. 1).

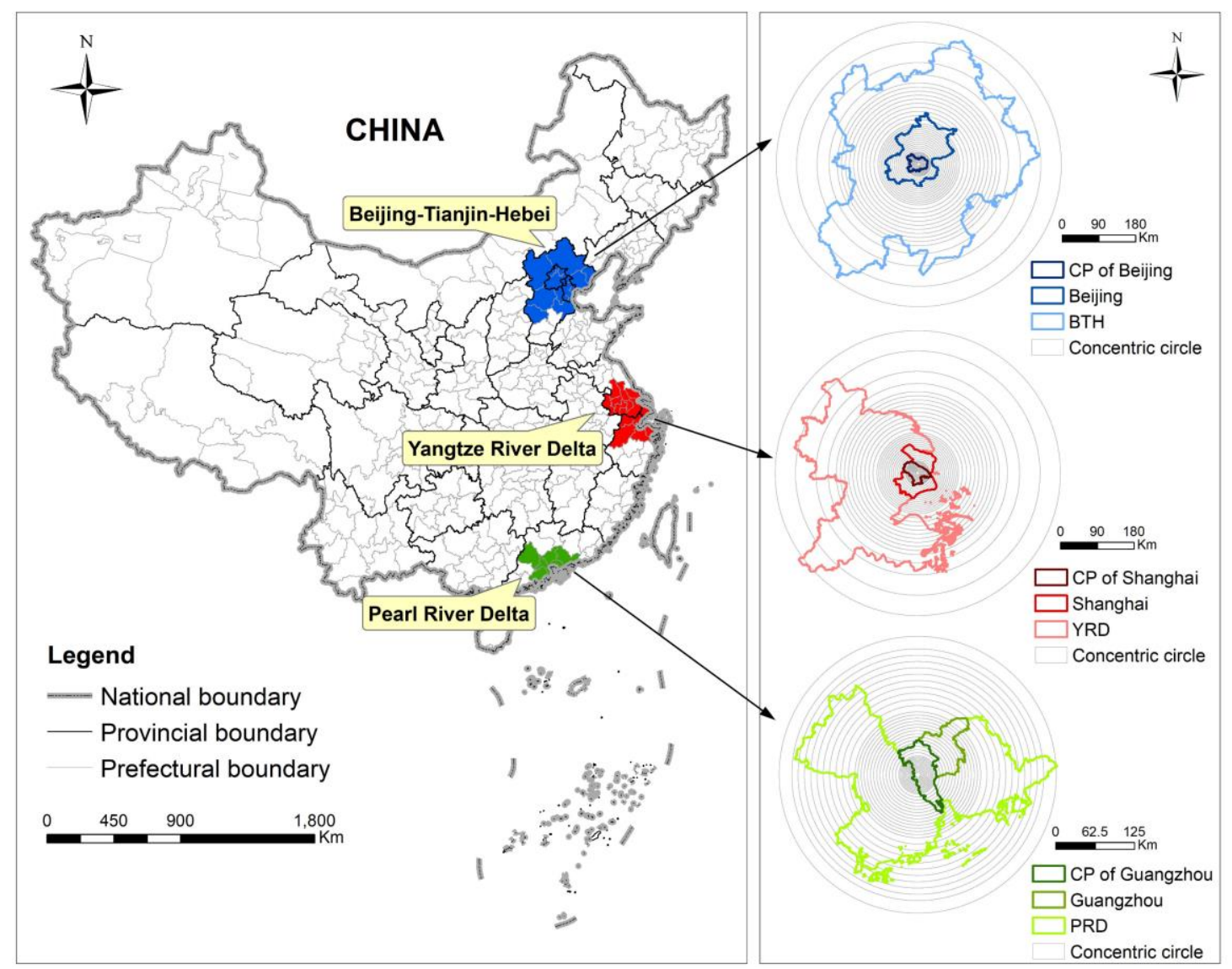

130 Fig. 1 Location and administrative hierarchy of study areas. The concentric circle illustrations on 131 the right represent the spatial extension of three urban agglomerations at the administrative 132 hierarchy levels. The CP of Beijing/Shanghai/Guangzhou refer to the city proper of Beijing/Shanghai/Guangzhou;

Beijing/Shanghai/Guangzhou refer to the Beijing/Shanghai/Guangzhou metropolitan region;

$\mathrm{BTH} / \mathrm{YRD} / \mathrm{PRD}$ refer to the Beijing-Tianjin-Hebei/Yangtze River Delta/Pearl River Delta urban agglomeration.

Data acquisition

For the three urban agglomerations, LULC data with a spatial resolution of $30 \times 30 \mathrm{~m}$ in 2018 were downloaded from the Resource and Environment Science and Data Center 139 (http://www.resdc.cn/). Digital elevation model data with a spatial resolution of $30 \times 30 \mathrm{~m}$ were 140 derived from the Geospatial Data Cloud (http://www.gscloud.cn/). Climate data, including the 
141 annual average precipitation and temperature in all meteorological stations, were collected from

142 the China Meteorological Data Service Center (http://data.cma.cn/). Potential evapotranspiration

143 data were collected from the Global Aridity and PET Database

144 (https://cgiarcsi.community/data/global-aridity-and-pet-database/). Soil properties data, including

145 bulk density, soil organic carbon, clay content, sand content, silt content, and soil depth, were

146 obtained from the World Soil Information database (https://soilgrids.org/).

\section{LULC maps in urban agglomerations}

148 LULC maps in 2018 for the BTH, YRD, and the PRD urban agglomerations were generated by 149 researchers at the Institute of Geographic Sciences and Natural Resources Research, Chinese 150 Academy of Sciences, through manual visual interpretation. The original data were Landsat 8 151 OLI_TIRS remote-sensing images that were downloaded from the United States Geological 152 Survey (https://www.usgs.gov/). The raster data comprised six LULC types: (1) cropland, 153 including irrigated cropland, dry cropland, and orchards; (2) forests, including natural forests, 154 artificial forests, coppice, shrub forests, and sparse forests; (3) grassland, including all types of 155 grasslands with coverage of more than 5\%, pastures, and hay; (4) water bodies, including rivers, 156 lakes, reservoirs, ponds, swamps, tidal lands, and wetlands; (5) developed land, including urban 157 construction land, rural residential land, industrial land, traffic road, airport, and mining area; and 158 (6) barren land, including sandy land, desert, saline land, swampland, bare land, bare rock, and 159 other unutilized lands.

\section{Quantifying multiple ES indicators in urban agglomerations}

161 This study selected eight ES indicators: carbon storage, food production, water yield, air 162 pollution removal, nitrogen retention, soil retention, habitat quality, and recreational opportunity. 163 The selection was based on three criteria: (1) the indicators belong to the basic provisioning, 164 regulating, and cultural services (Millennium Ecosystem Assessment 2005); (2) they have great 165 significance to the sustainable development of three urban agglomerations (Liu et al. 2018; Luo et 166 al. 2020; Sun et al. 2018; Zhang et al. 2017); and (3) they can comprehensively reflect the 167 characteristics of complex urban ecosystems and represent the information of water resources, 168 food, climate, soil, habitat, and culture in urban agglomerations.

169 We used the Integrated Valuation of Ecosystem Services and Tradeoffs (InVEST) model to 170 quantify the carbon storage, water yield, nitrogen retention, soil retention, and habitat quality for 171 the three urban agglomerations. Food production was estimated by using the Global 172 Agro-Ecological Zones (GAEZ) model. The removal of $\mathrm{PM}_{2.5}$ (atmospheric aerosol particles with 173 a diameter of less than $2.5 \mu \mathrm{m}$ ) was estimated on the basis of the adsorption capacity of vegetation 174 to $\mathrm{PM}_{2.5}$ pollutants. Recreational opportunity was quantified by the Recreation opportunity 175 Spectrum (ROS) model. Table 1 listed the ES indicators and assessment descriptions. In addition, 176 the calculation process and detailed parameters were shown in Supplementary Information (SI). 
179 Descriptions of ecosystem service (ES) indicators and the assessment methods

\begin{tabular}{ll}
\hline ES types & Principles and descriptions of ES assessment models \\
\hline Carbon storage & The InVEST Carbon Storage and Sequestration model maps the carbon densities of \\
& different land use/land cover (LULC) types and summarizes the results into aggregate \\
& storage values (Goldstein et al. 2012). \\
Food production & The food production potential was calculated by considering the limiting factors, such as \\
& water resource, soil properties, topographic conditions, cultivated land distribution, and \\
management measures (Liu et al. 2015). & The InVEST Water Yield model estimates the water of different landscape areas. It is \\
Water yield & based on the principle of water balance on a grid map (Sharp et al. 2020). \\
PM2.5 removal & The PM2.5 removal was calculated on the basis of the adsorption of PM2.5 per unit area \\
for different LULC types. & The InVEST Nutrient Delivery Ratio model assesses nitrogen retention according to the \\
Nitrogen & nutrient pollutants removed by vegetation and soil in surface runoff (Sharp et al. 2020). \\
retention & The InVEST Sediment Delivery model computes sediment retention based on the \\
Soil retention & amount of soil loss and its delivery ratio (Hamel et al. 2015). \\
Habitat quality & $\begin{array}{l}\text { The InVEST Habitat Quality model combines the information of LULC types and } \\
\text { threats to biodiversity to produce habitat quality maps (Sharp et al. 2020). } \\
\text { Recreational }\end{array}$ \\
The ROS model was associated with the recreational index and accessibility index for \\
reaching the recreational locations (Lavorel et al. 2020).
\end{tabular}

Quantifying the scaling relations of LULC and ESs with respect to spatial extent

182 ES supply depends on ecosystem structures and processes. Thus, LULC change has become a 183 major driving force that impacts regional ecosystem change (Hasan et al. 2020). Both LULC 184 compositions and configuration are expected to significantly impact ESs (Lei et al. 2021). 185 Therefore, exploring how LULC change responds to increased spatial extent is an important basis 186 for understanding and explaining the spatial scaling effect of ESs. The form of scalograms (Frazier 187 2016; Ma et al. 2019; Wu 2004) was adopted in this study to reflect how different LULC types 188 and ESs respond to changing spatial extents in three urban agglomerations. A series of concentric 189 circles with gradually expanding radii were used to represent the expansion of spatial extent across 190 urban hierarchical levels (Fig. 1, Table 2). The spatial extent was expressed as the radius of a 191 concentric circle. Thus, scalograms were constructed by plotting the changes of LULC and ESs 192 with respect to increasing spatial extents (Wu 2004). 
195 The radii list of concentric circles at different administrative hierarchical levels for BTH, YRD,

196 and PRD urban agglomerations (Unit: km).

\begin{tabular}{|c|c|c|c|c|c|c|c|c|}
\hline \multicolumn{3}{|c|}{ BTH urban agglomeration } & \multicolumn{3}{|c|}{ YRD urban agglomeration } & \multicolumn{3}{|c|}{ PRD urban agglomeration } \\
\hline $\mathrm{CP}$ of Beijing & Beijing & BTH & $\mathrm{CP}$ of Shanghai & Shanghai & YRD & CP of Guangzhou & Guangzhou & PRD \\
\hline 4 & 4 & 4 & 4 & 4 & 4 & 4 & 4 & 4 \\
\hline 6 & 6 & 6 & 6 & 6 & 6 & 6 & 6 & 6 \\
\hline 8 & 8 & 8 & 8 & 8 & 8 & 8 & 8 & 8 \\
\hline 10 & 10 & 10 & 10 & 10 & 10 & 10 & 10 & 10 \\
\hline 12 & 12 & 12 & 12 & 12 & 12 & 12 & 12 & 12 \\
\hline 14 & 14 & 14 & 14 & 14 & 14 & 14 & 14 & 14 \\
\hline 16 & 16 & 16 & 16 & 16 & 16 & 16 & 16 & 16 \\
\hline 18 & 18 & 18 & 18 & 18 & 18 & 18 & 18 & 18 \\
\hline 20 & 20 & 20 & 20 & 20 & 20 & 20 & 20 & 20 \\
\hline 22 & 22 & 22 & 22 & 22 & 22 & 22 & 22 & 22 \\
\hline 24 & 24 & 24 & 24 & 24 & 24 & 24 & 24 & 24 \\
\hline 26 & 26 & 26 & 26 & 26 & 26 & 26 & 26 & 26 \\
\hline 28 & 28 & 28 & 28 & 28 & 28 & 28 & 28 & 28 \\
\hline 30 & 30 & 30 & 30 & 30 & 30 & 30 & 30 & 30 \\
\hline & 35 & 35 & 35 & 35 & 35 & 35 & 35 & 35 \\
\hline & 40 & 40 & 40 & 40 & 40 & 40 & 40 & 40 \\
\hline & 45 & 45 & & 45 & 45 & 45 & 45 & 45 \\
\hline & 50 & 50 & & 50 & 50 & 50 & 50 & 50 \\
\hline & 55 & 55 & & 55 & 55 & 55 & 55 & 55 \\
\hline & 60 & 60 & & 60 & 60 & 60 & 60 & 60 \\
\hline & 65 & 65 & & 65 & 65 & 65 & 65 & 65 \\
\hline & 70 & 70 & & 70 & 70 & 70 & 70 & 70 \\
\hline & 75 & 75 & & & 75 & & 75 & 75 \\
\hline & 80 & 80 & & & 80 & & 80 & 80 \\
\hline & 85 & 85 & & & 85 & & 85 & 85 \\
\hline & 90 & 90 & & & 90 & & 90 & 90 \\
\hline & 95 & 95 & & & 95 & & 95 & 95 \\
\hline & 100 & 100 & & & 100 & & 100 & 100 \\
\hline & 110 & 110 & & & 110 & & 110 & 110 \\
\hline & 120 & 120 & & & 120 & & 120 & 120 \\
\hline & 130 & 130 & & & 130 & & & 130 \\
\hline & & 140 & & & 140 & & & 140 \\
\hline & & 150 & & & 150 & & & 150 \\
\hline & & 160 & & & 160 & & & 160 \\
\hline & & 170 & & & 170 & & & 170 \\
\hline & & 180 & & & 180 & & & 180 \\
\hline & & 190 & & & 190 & & & 190 \\
\hline & & 200 & & & 200 & & & 200 \\
\hline & & 220 & & & 220 & & & 220 \\
\hline & & 250 & & & 250 & & & \\
\hline & & 300 & & & 300 & & & \\
\hline & & 350 & & & 350 & & & \\
\hline
\end{tabular}

Note: The center of concentric circles is the administrative center of a city proper. For each urban hierarchical level,

198 the concentric circle with the maximum radius can cover the boundary of the corresponding level. BTH/YRD/PRD

199 represents the Beijing-Tianjin-Hebei/Yangtze River Delta/Pearl River Delta urban agglomeration, CP of

200 Beijing/Shanghai/Guangzhou refers to the city proper of Beijing/Shanghai/Guangzhou.

Using SPSS 25.0, we adopted the curve estimation regression models (Jomnonkwao et al. 2020) to investigate the scaling relations. The coefficient of determination $\left(\mathrm{R}^{2}\right)$ was used to indicate the goodness of fit of the curve (Massada and Radeloff 2010). The independent variable (X) was the radius of the concentric circle (spatial extent). The dependent variable (Y) was the proportion of LULC or the average ES value within the corresponding concentric circle area. 


\section{Results}

Scaling relations of LULC for three urban agglomerations

209 For the three urban agglomerations, proportions of developed land decreased as the spatial

210 extent increased. In contrast, the proportions of forests and cropland increased with the expansion

211 of the spatial scale. The proportion of water bodies showed irregular fluctuations with the

212 expansion of scale. In addition, the proportion of grassland in BTH increased when the spatial

213 scale expanded. Further, the proportions of grassland and barren land were exceedingly small in

214 YRD and PRD (Fig. 2, Fig. 3).

215
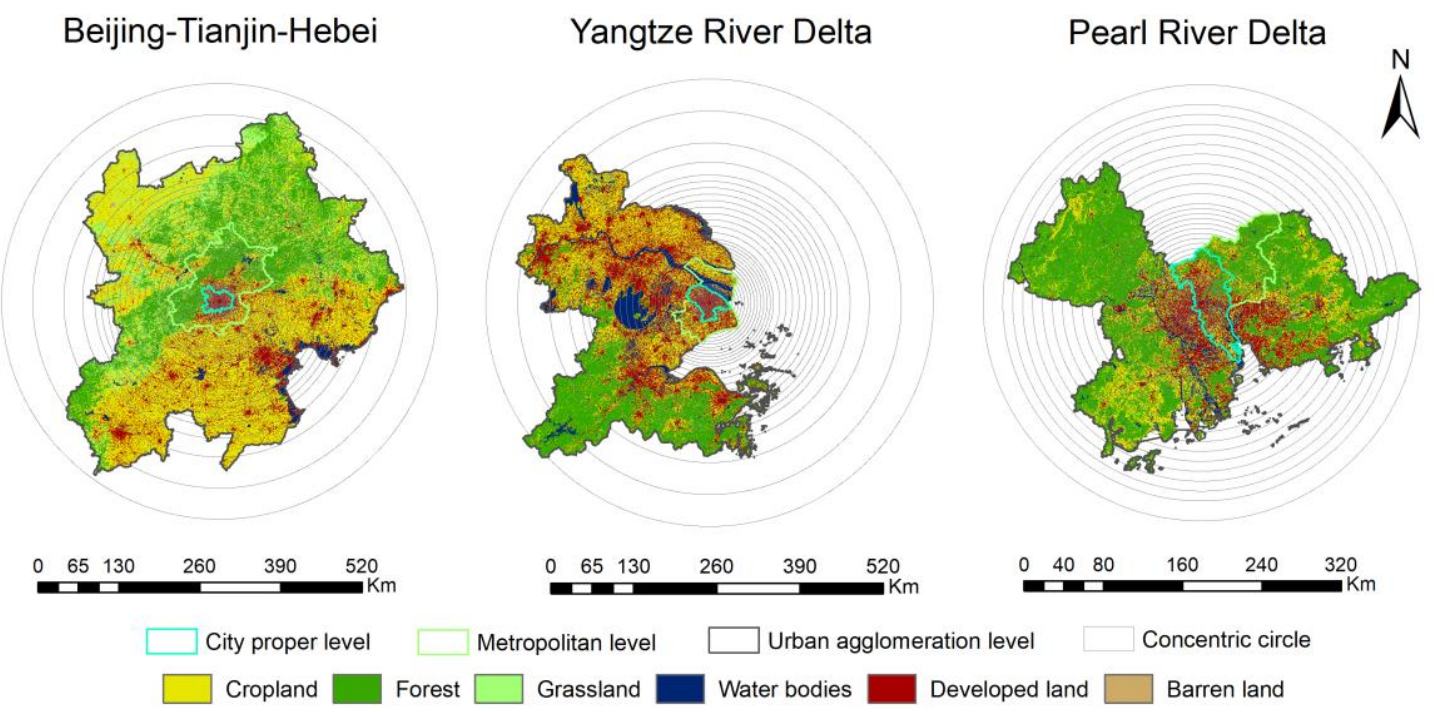
Forest

Grassland

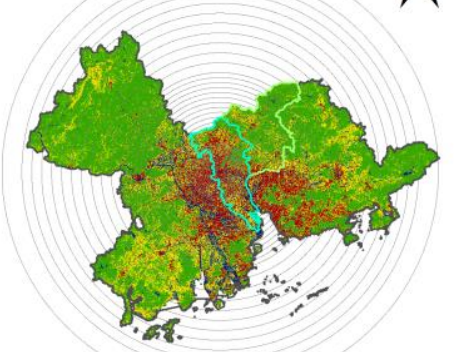

Fig. 2 Spatial distributions of land use/land cover in 2018 for three urban agglomerations. The radii list of concentric circles is shown in Table 2. 
(a) City proper of Beijing

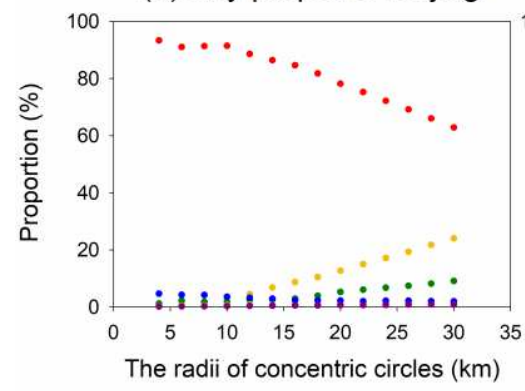

(b) Beijing metropolitan region

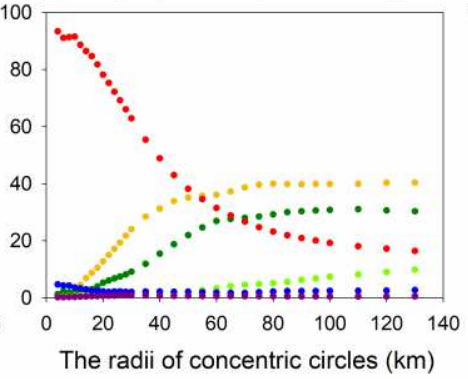

(d) City proper of Shanghai

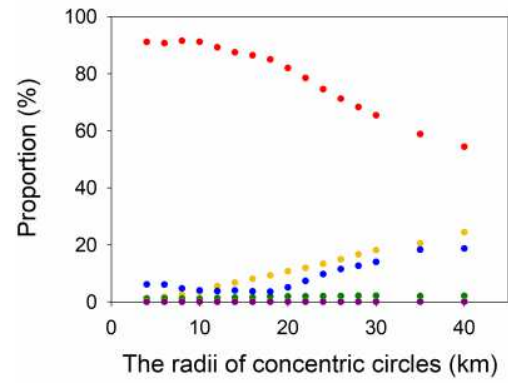

(e) Shanghai metropolitan region

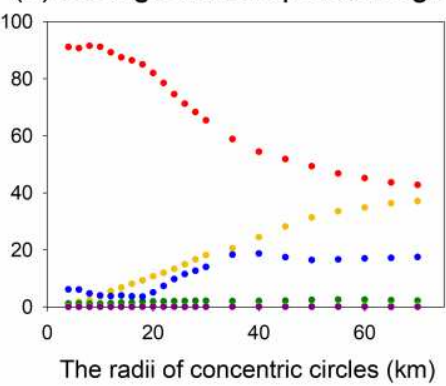

(c) BTH urban agglomeration

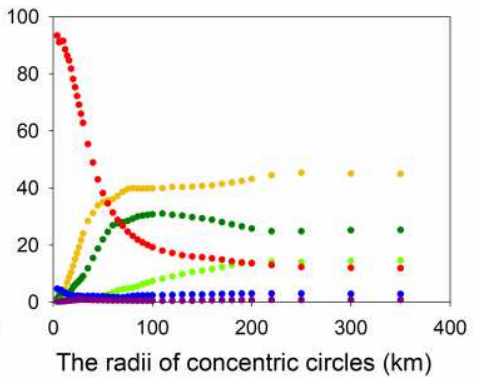

(f) YRD urban agglomeration

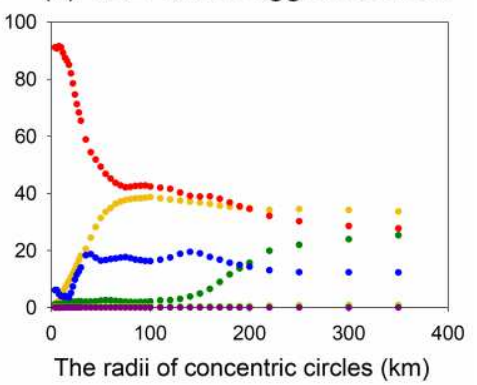

(g) City proper of Guangzhou (h)

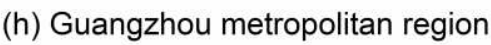

(i) PRD urban agglomeration
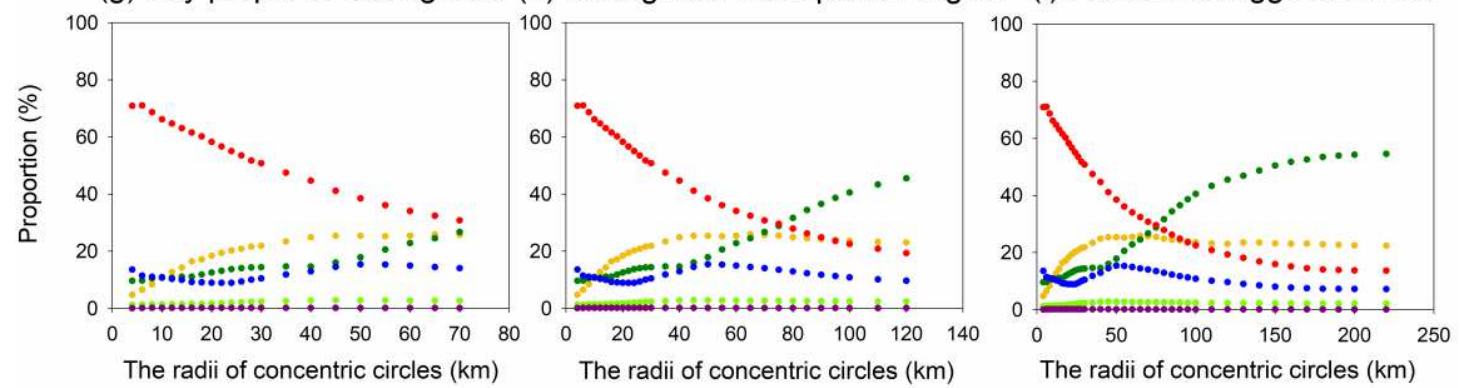

Fig. 3 Scalograms of the proportion of different land use/land cover types with respect to increasing concentric circle radii in the three largest urban agglomerations of China (Beijing-Tianjin-Hebei (BTH), Yangtze River Delta (YRD), and Pearl River Delta (PRD)).

Overall, the proportions of cropland, forest, and developed land exhibited appropriate and predictable scaling laws at certain levels of urban hierarchy. The typical scaling curves for different urban hierarchical levels were classified into three rules: linear, sigmoidal, and exponential relationships. Among them, the exponential relationships were divided into exponential growth and exponential decay (Fig. A1). However, the scaling relations of water bodies and barren land were unpredictable at nearly all three urban hierarchical levels. The proportion of grassland showed scaling laws in BTH, but this was unpredictable in YRD and PRD (Table 3).

For the BTH area, the linear scaling relations were found at the city proper level for most of the land use types. Next, the general relationships were converted into exponential and sigmoidal functions at the broader metropolitan and urban agglomeration levels. For YRD, most of the 
LULC types did not reveal the scaling relations and functions except for cropland and developed land. Both showed linear relationships at the city proper level and sigmoidal and exponential growth or exponential decay at higher urban hierarchical levels, respectively. For PRD, the cropland, forest, and developed land scaled in a predictable way. The proportions of cropland increased with exponential curves, while forest increased with sigmoidal curves. The proportions of developed land decreased in a linear relationship at the city proper level, while it converted to exponential decay at the higher levels (Table 3).

\section{Table 3}

Type of scaling relations for proportions of different land use/land cover with respect to increasing radii of concentric circles within the three largest urban agglomerations

\begin{tabular}{|c|c|c|c|c|}
\hline \multirow{2}{*}{ Urban agglomeration } & \multirow{2}{*}{$\begin{array}{l}\text { Land use/land } \\
\text { cover types }\end{array}$} & \multicolumn{3}{|c|}{ Urban hierarchical levels } \\
\hline & & City proper & Metropolitan region & Urban agglomeration \\
\hline \multirow{6}{*}{ Beijing-Tianjin-Hebei } & Cropland & Linear & Sigmoidal & Exponential growth \\
\hline & Forest & Linear & Exponential growth & - \\
\hline & Grassland & Linear & Exponential growth & Sigmoidal \\
\hline & Water bodies & Exponential decay & - & - \\
\hline & Developed land & Linear & Exponential decay & Exponential decay \\
\hline & Barren land & Linear & - & - \\
\hline \multirow{6}{*}{ Yangtze River Delta } & Cropland & Linear & Sigmoidal & Exponential growth \\
\hline & Forest & - & - & Sigmoidal \\
\hline & Grassland & - & - & - \\
\hline & Water bodies & - & - & - \\
\hline & Developed land & Linear & Exponential decay & Exponential decay \\
\hline & Barren land & - & - & - \\
\hline \multirow{6}{*}{ Pearl River Delta } & Cropland & Exponential growth & Exponential growth & Exponential growth \\
\hline & Forest & Sigmoidal & Sigmoidal & Sigmoidal \\
\hline & Grassland & Sigmoidal & - & - \\
\hline & Water bodies & - & - & - \\
\hline & Developed land & Linear & Exponential decay & Exponential decay \\
\hline & Barren land & - & - & - \\
\hline
\end{tabular}

Note: The archetypes of scaling relations were shown in Fig. A1. For all scaling relation equations in Table 3, the relationships between the proportions of land use/land cover types and the increasing spatial extents were significant $\left(* * \mathrm{P}<0.001, \mathrm{R}^{2}>0.990\right)$.

\section{Scaling relations of multiple ESs in BTH}

251 For the spatial patterns of multiple ESs in BTH, the values for most of ESs become higher with 252 increasing spatial extent, except for water yield and soil retention (Fig. 4). According to the 253 scalograms of multiple ESs, with respect to increasing spatial extent in BTH, the carbon storage, 254 food production, water yield, $\mathrm{PM}_{2.5}$ removal, nitrogen retention, and the habitat quality revealed 255 significant and predictable scaling relations at different urban hierarchical levels. However, the 256 soil retention did not show any scaling relations. In general, the two form functions, which were power law and exponential functions, can fit the scaling relations of ESs better in the BTH 
agglomeration. The ESs showed pervasive power law scaling relations at the city proper level

259 while exhibiting exponential scaling relations at the higher metropolitan and urban agglomeration 260 levels (Fig. 5).

261

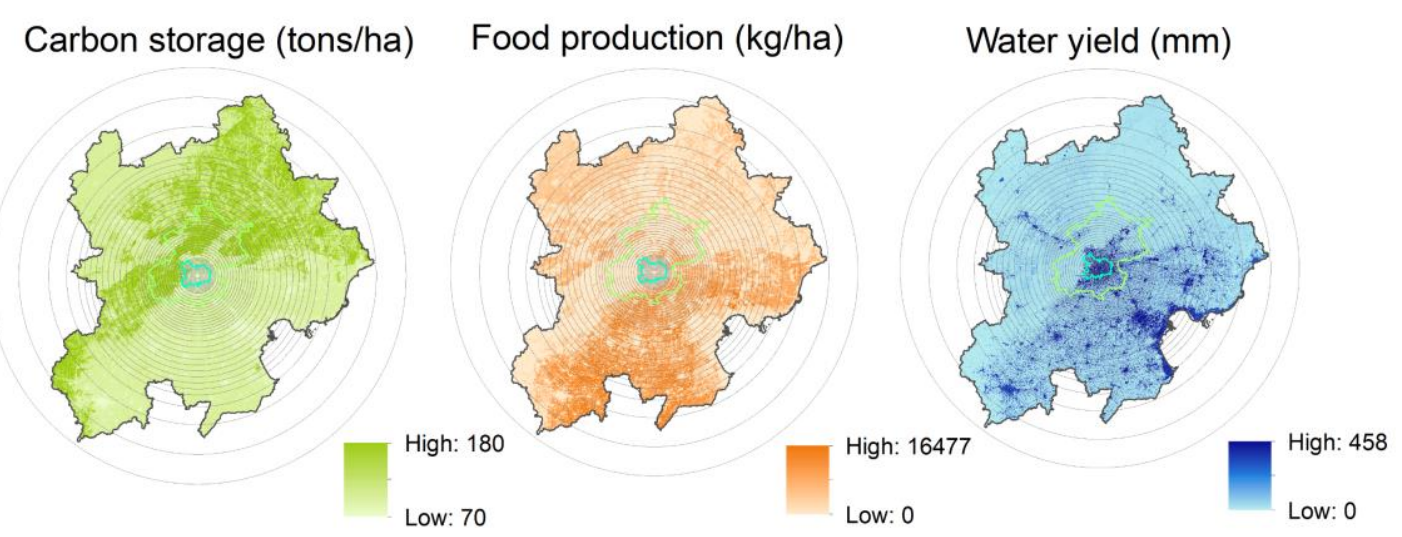

PM2.5 removal $(\mathrm{kg} / \mathrm{ha}) \quad$ Nitrogen retention $(\mathrm{kg} / \mathrm{ha}) \quad$ Soil retention (tons $/ \mathrm{ha})$
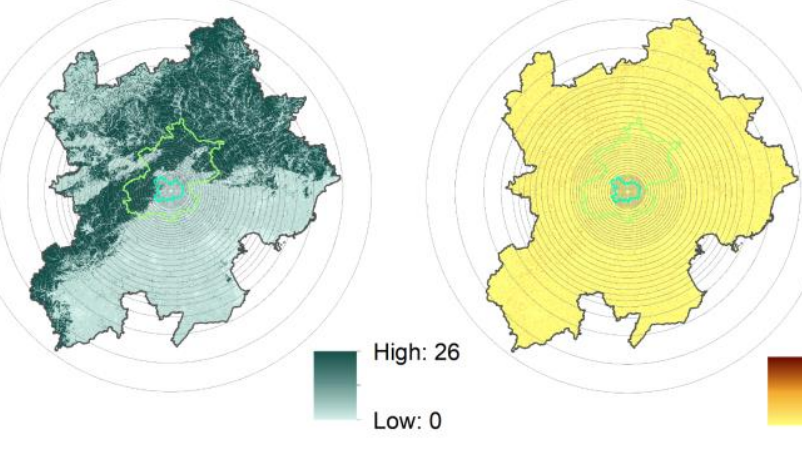

Low: 0
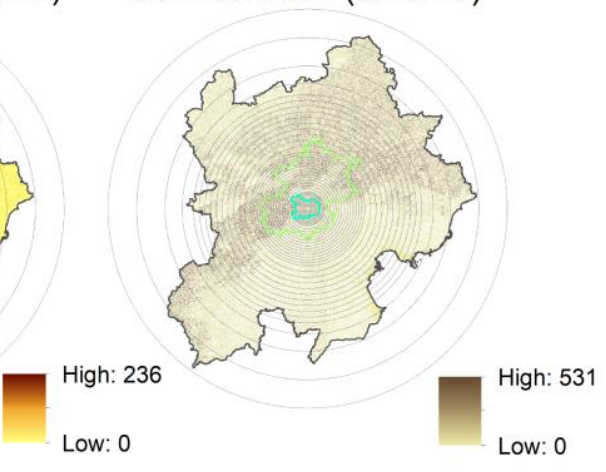

Habitat quality index Recreational opportunity index
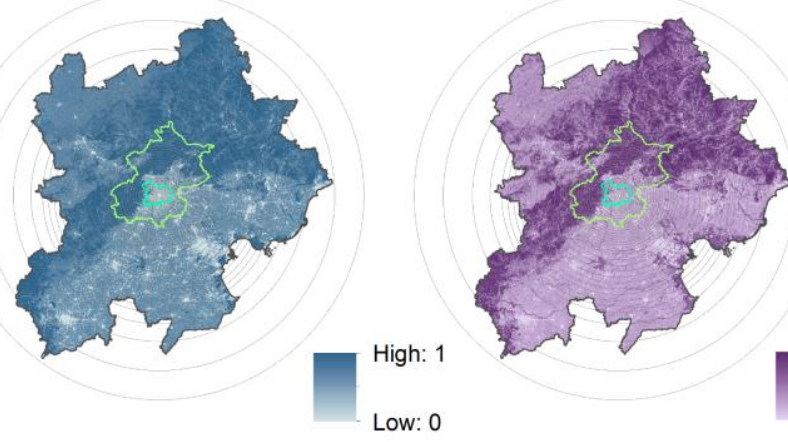

$N$

City proper of Beijing Beijing metropolitan region BTH urban agglomeration Concentric circle

Fig. 4 Spatial distributions of multiple ecosystem services in 2018 for Beijing-Tianjin-Hebei (BTH) urban agglomeration. The radii list of concentric circles was shown in Table 2. 

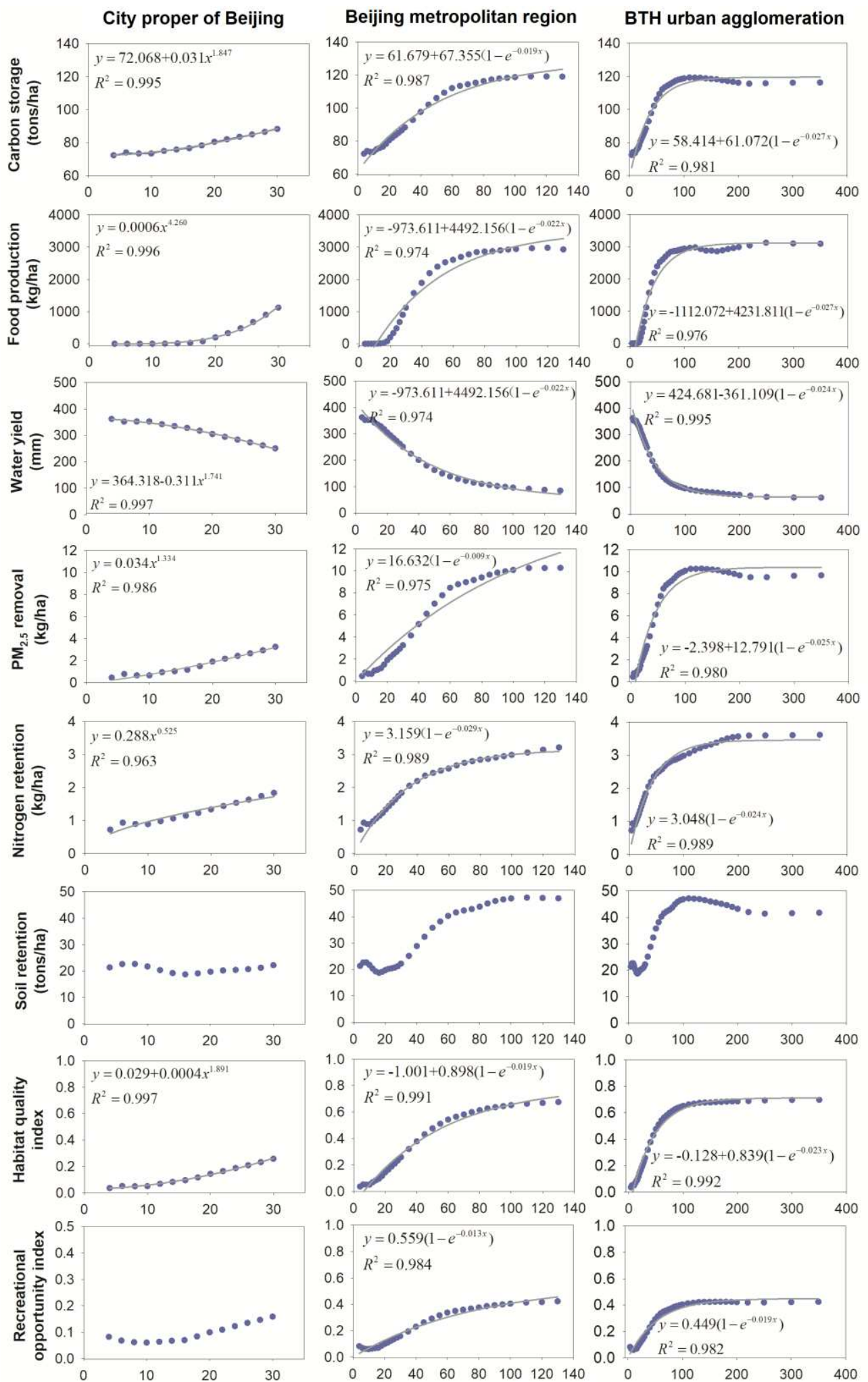

The radii of concentric circles $(\mathbf{k m})$ The radii of concentric circles $(\mathbf{k m})$ The radii of concentric circles $(\mathrm{km})$

267 Fig. 5 Scalograms of multiple ecosystem service indicators with respect to increasing concentric circle radii at various urban hierarchical levels: the city proper of Beijing, Beijing metropolitan region, and the Beijing-Tianjin-Hebei $(\mathrm{BTH})$. For all regression curves and equations, the significance level P-values $<0.001$. 
272 Specifically, the values of carbon storage, food production, $\mathrm{PM}_{2.5}$ removal, and habitat quality 273 increased consistently and followed a power law function with a scaling exponent of greater than

2741 within the city proper of Beijing. As the spatial extent increased in the metropolitan region and

275 urban agglomeration, the indicator values showed exponential functions with negative exponents.

276 For nitrogen retention, the scaling exponent was smaller than 1 in the power law function within

277 the city proper of Beijing. As the spatial extent increased beyond the city proper, the nitrogen

278 retention values also showed an exponential function with a negative exponent and continued to

279 increase until it eventually remained stable. In addition to these increasing indicators, the water

280 yield showed a decreasing trend with the expansion of spatial extent. The index values followed a

281 power law decline within the city proper of Beijing. They continued to decrease with exponential

282 scaling relations at higher urban hierarchical levels. For recreational opportunities, the index

283 values first decreased and then increased with the increasing spatial extent within the city proper.

284 As the spatial extent increased, the index values followed exponential functions and continued to 285 grow until it stabilized (Fig. 5).

286 Scaling relations of multiple ESs in YRD

287 For the spatial patterns of multiple ESs in YRD, the values for most of ESs become higher with 288 increasing spatial extent, except for water yield, nitrogen retention, and soil retention (Fig. 6). 289 According to the scalograms of multiple ESs of the increasing spatial extent in YRD, only food 290 production and water yield displayed universal and predictable scaling relations at different urban 291 hierarchical levels. For carbon storage, $\mathrm{PM}_{2.5}$ removal, and habitat quality, the index values 292 followed predictable scaling relations within the Shanghai metropolitan region. As the spatial 293 extent further increased beyond the metropolitan region, the scaling relations became 294 unpredictable. In addition, for nitrogen retention, soil retention, and recreational opportunities, 295 there were no predictable scaling relations that could fit the curves (Fig. 7). 


\section{Carbon storage (tons/ha) Food production $(\mathrm{kg} / \mathrm{ha}) \quad$ Water yield $(\mathrm{mm})$}
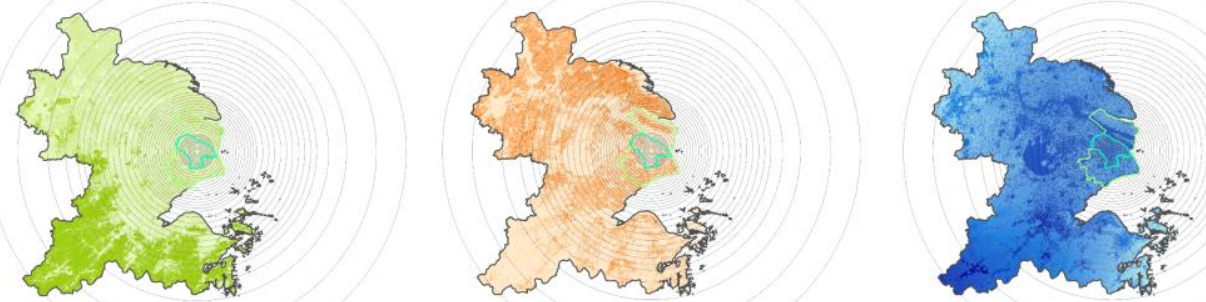

High: 206
Low: 87

High: 19279

High: 2026

Low: 0

PM2.5 removel $(\mathrm{kg} / \mathrm{ha})$

Nitrogen retention $(\mathrm{kg} / \mathrm{ha})$

Soil retention (tons/ha)
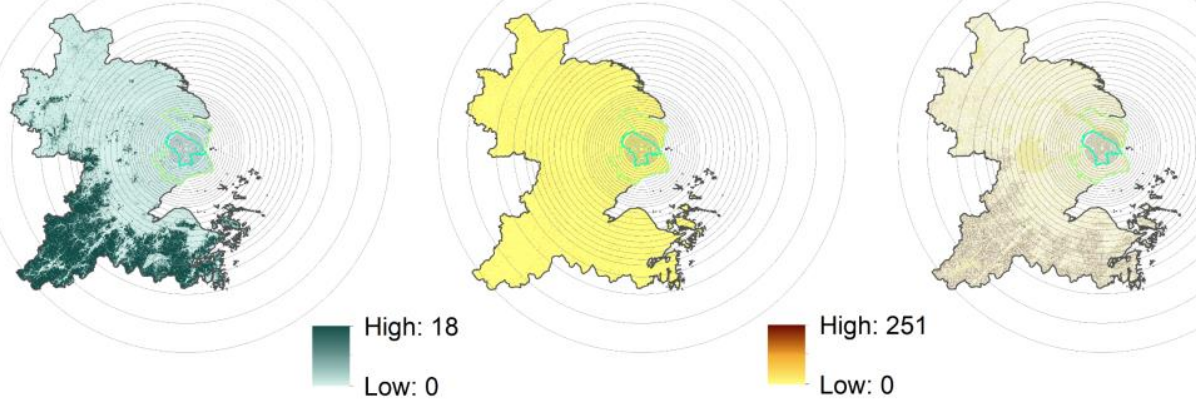

High: 648

Low: 0

Habitat quality index Recreational opportunity index
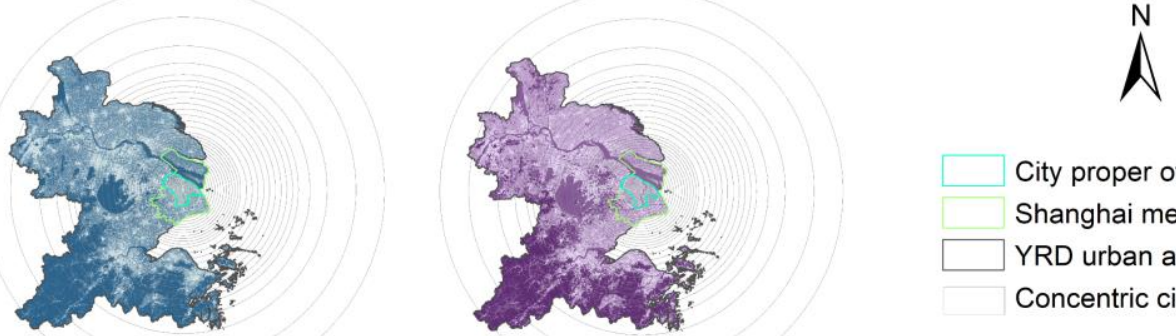

Fig. 6 Spatial distributions of multiple ecosystem services in 2018 for Yangtze River Delta (YRD) urban agglomeration. The radii list of concentric circles was shown in Table 2. 

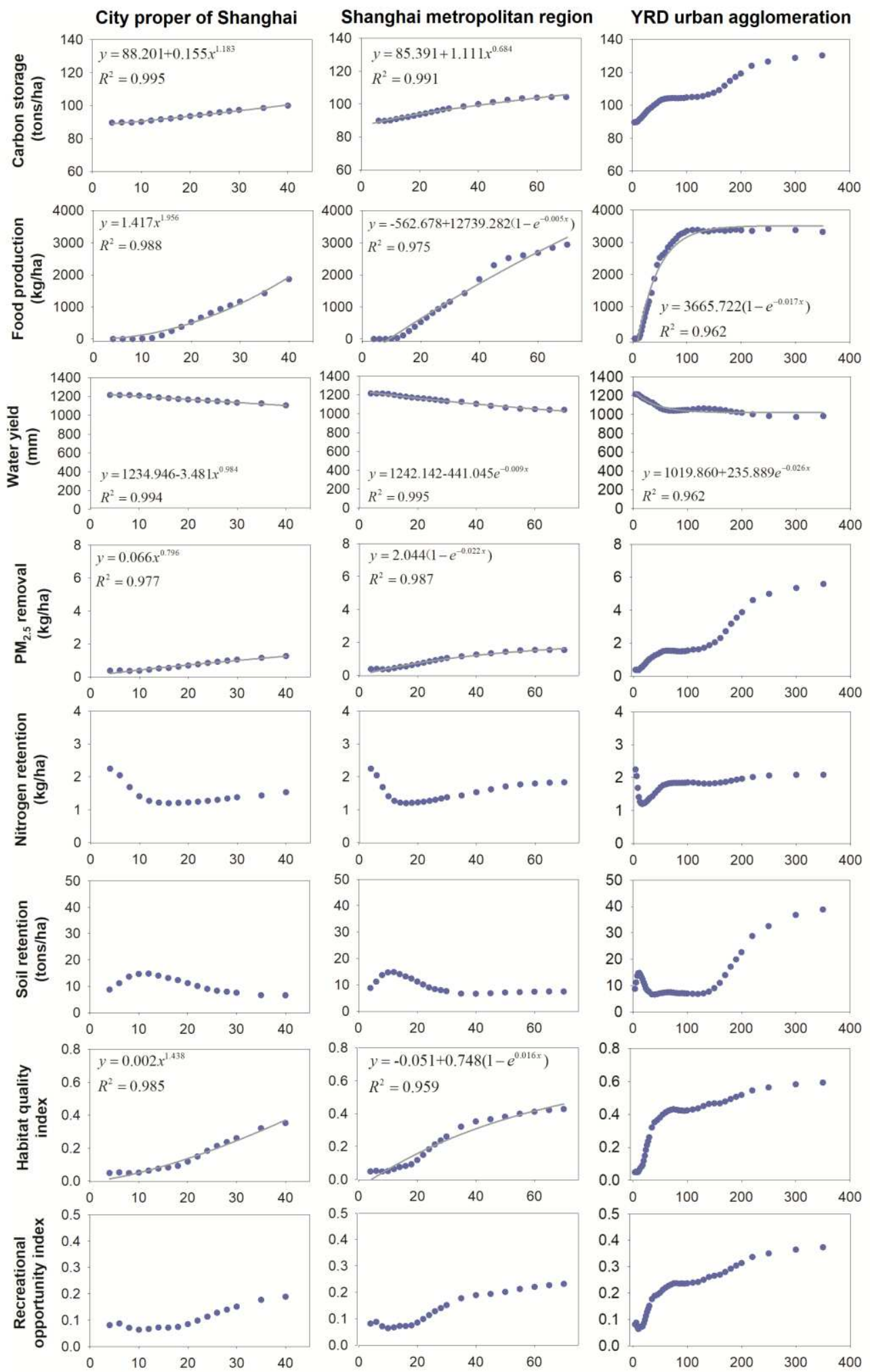

The radii of concentric circles $(\mathbf{k m})$ The radii of concentric circles $(\mathbf{k m})$ The radii of concentric circles $(\mathbf{k m})$

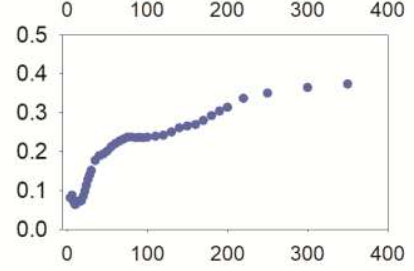

Fig. 7 Scalograms of multiple ecosystem service indicators with respect to increasing concentric circle radii at various urban hierarchical levels: the city proper of Shanghai, Shanghai metropolitan region, and the Yangtze River Delta (YRD). For all regression curves and equations, the significance level P-values $<0.001$. 
Specifically, food production values increased with a power law scaling relationship at the city proper level, while it showed exponential growth scaling relationships at higher urban hierarchical levels. Water yield values decreased with a power law scaling relation at the city proper level, followed by exponential decay scaling as the spatial extent covered the metropolitan region and urban agglomeration. For carbon storage, $\mathrm{PM}_{2.5}$ removal, and habitat quality, the index values exhibited power law scaling relations within the city proper of Shanghai. As the spatial extent

312 further increased to the Shanghai metropolitan region, carbon storage still followed a power law function, while $\mathrm{PM}_{2.5}$ removal and habitat quality followed an exponential growth relationship.

314 The values of these three ESs showed upward staircase-like curves when the spatial extent 315 increased to urban agglomeration. In addition, the values of nitrogen retention did not change 316 significantly at various urban hierarchical levels. The soil retention values performed best when spatial extent increased beyond the metropolitan region. The recreational opportunity index values showed an upward staircase-like curve with increasing spatial extent (Fig. 7).

\section{Scaling relations of multiple ESs in PRD}

For the spatial patterns of multiple ESs in PRD, the values for most of ESs become higher with increasing spatial extent, except for water yield and soil retention (Fig. 8). According to the scalograms of multiple ESs, with respect to increasing spatial extent in PRD, the carbon storage, food production, water yield, $\mathrm{PM}_{2.5}$ removal, nitrogen retention, and habitat quality all exhibited predictable scaling relationships at different urban hierarchical levels. As with the BTH agglomeration, the scaling relationships of soil retention in PRD were unpredictable. The recreational opportunity showed a predictable scaling relation only at the urban agglomeration level. In general, the scaling relationship also presented two types of functions, which were power law and exponential relationships. Moreover, exponential relationships predominantly existed at higher urban hierarchical levels (Fig. 9). 


\section{Carbon storage (tons $/ \mathrm{ha}) \quad$ Food production $(\mathrm{kg} / \mathrm{ha}) \quad$ Water yield $(\mathrm{mm})$}
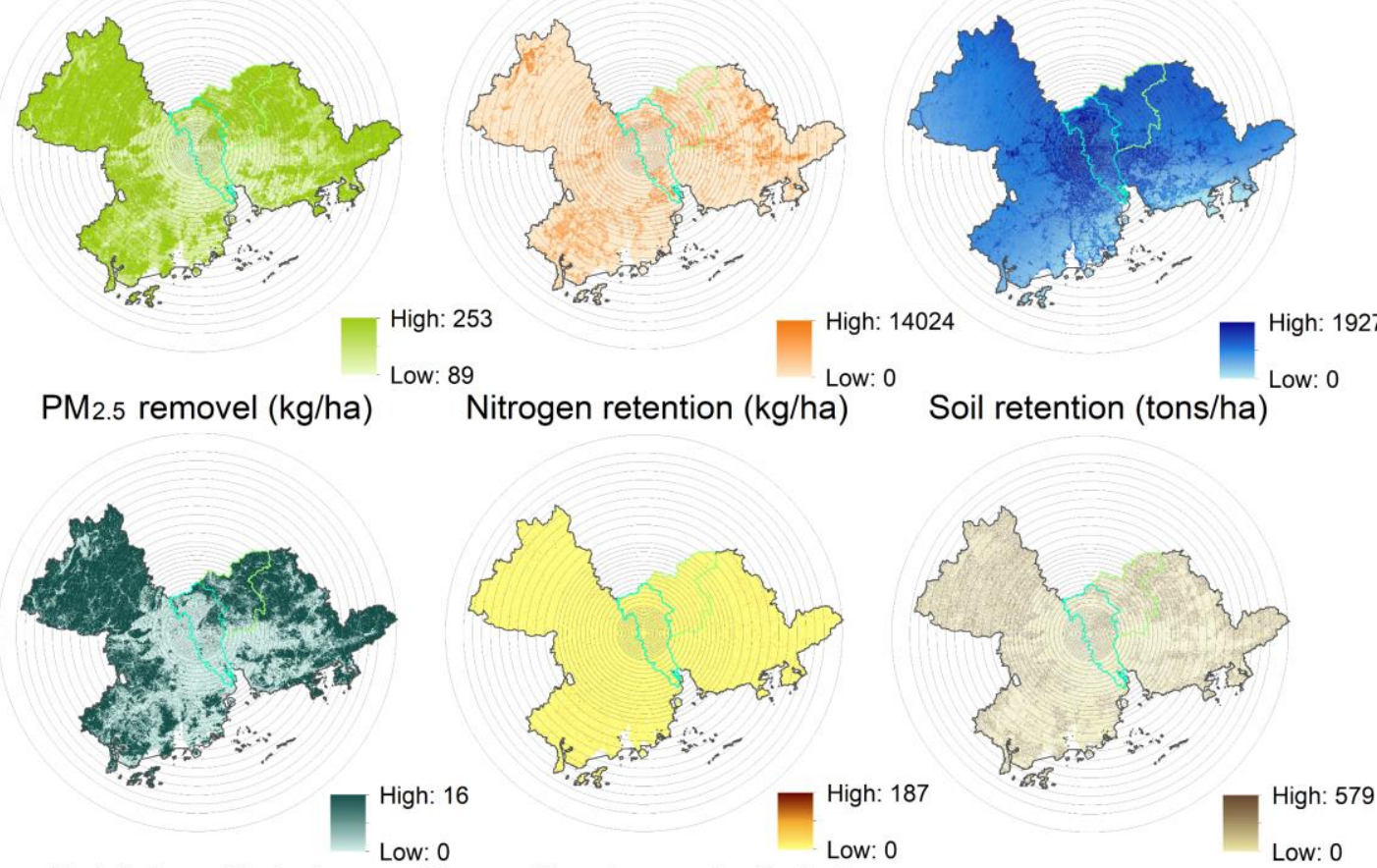

Habitat quality index

Recreational opportunity index
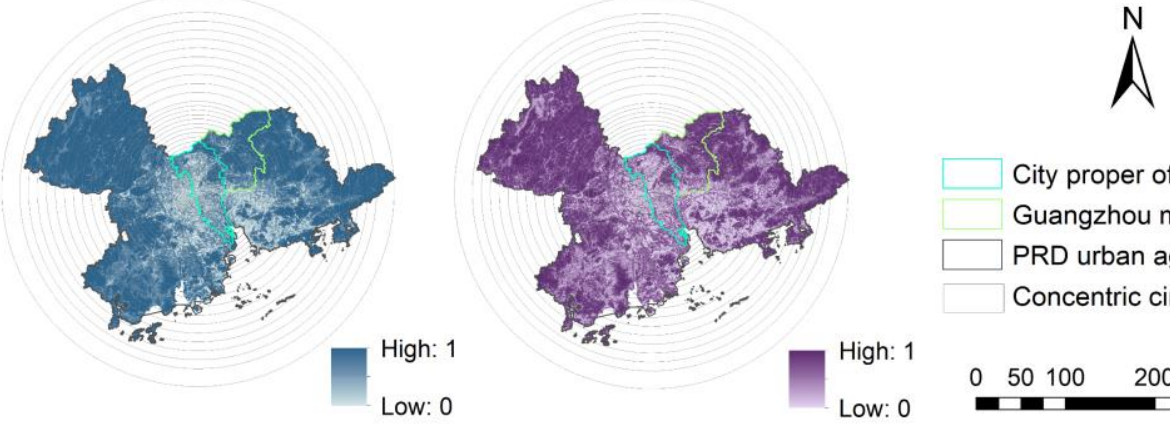

City proper of Guangzhou Guangzhou metropolitan region PRD urban agglomeration Concentric circle

Fig. 8 Spatial distributions of multiple ecosystem services in 2018 for Pearl River Delta (PRD) urban agglomeration. The radii list of concentric circles was shown in Table 2 . 


\section{City proper of Guangzhou Guangzhou metropolitan region PRD urban agglomeration}
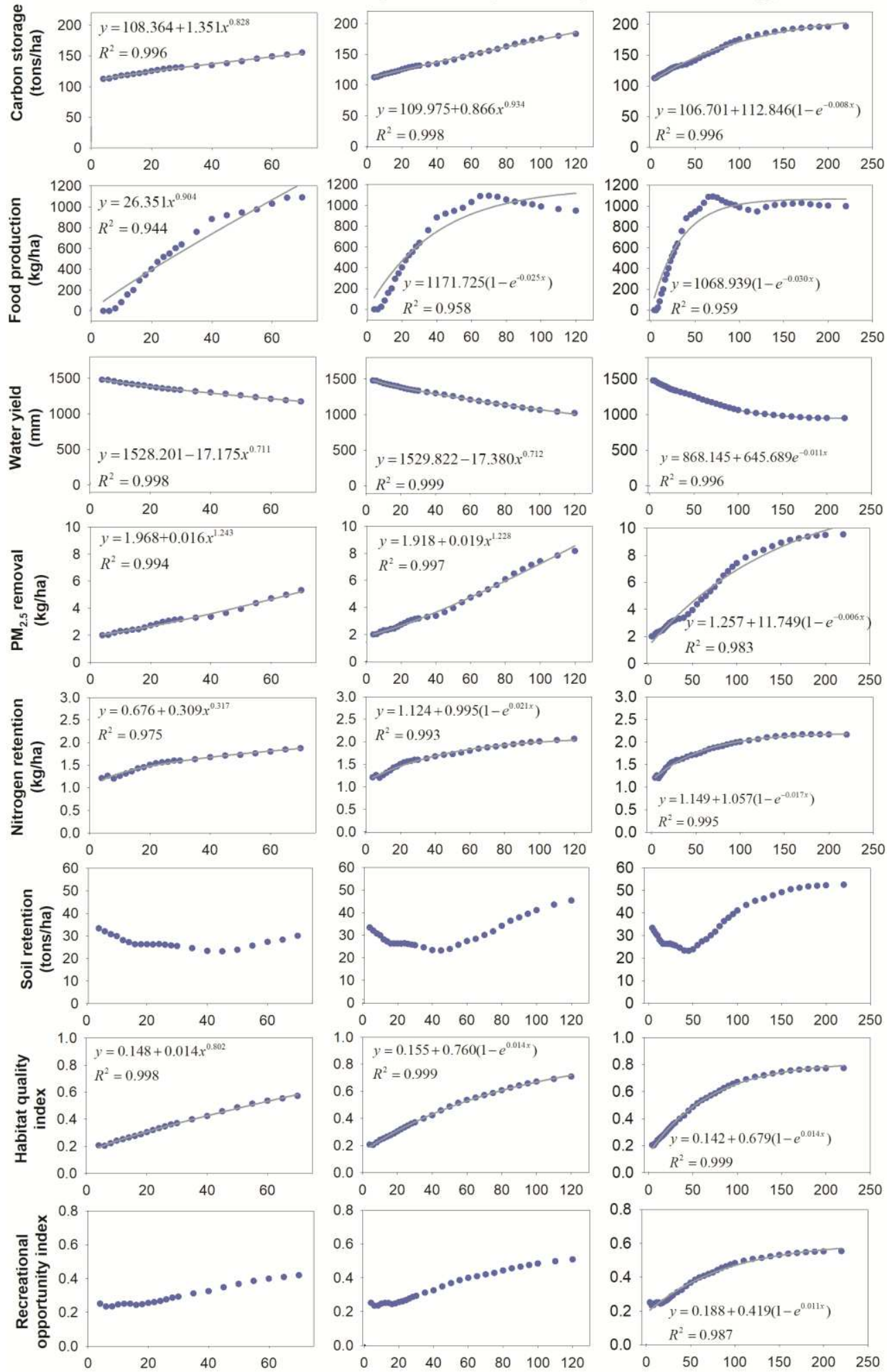

The radii of concentric circles $(\mathrm{km})$ The radii of concentric circles $(\mathrm{km})$ The radii of concentric circles $(\mathrm{km})$

336 Fig. 9 Scalograms of multiple ecosystem service indicators with respect to increasing concentric circle radii at various urban hierarchical levels: the city proper of Guangzhou, Guangzhou metropolitan region, and the Pearl River Delta (PRD). For all regression curves and equations, the significance level P-values $<0.001$. 

metropolitan region. Thereafter, they showed exponential functions as the spatial extent further increased to the urban agglomeration. The values of food production, nitrogen retention, and habitat quality followed power law functions within the city proper and then increased exponentially as the spatial extent increased beyond the city proper. For water yield, the index values showed a monotonously decreasing trend as the spatial extent increased. The index values followed the power law functions within the Guangzhou metropolitan region and then showed the exponential function as the spatial extent increased. For recreational opportunity, the index values began to follow an exponential function only when the spatial extent increased to the urban agglomeration level (Fig. 9).

\section{Discussion}

351 How did the scaling relations of LULC change across different urban hierarchical levels and agglomerations?

Different LULC types showed diversified distribution trends when the spatial extent increased. The developed lands exhibited decreasing trends from city proper outwards when croplands and forests showed an increasing trend. This was mainly because croplands and forests were substantially occupied by developed land during the rapid process of urbanization in China, especially for large urban agglomerations (Zhou et al. 2021; Kuang et al. 2020b). In contrast, water bodies and grasslands showed irregular and random characteristics with the increase of spatial extent. This phenomenon was predominantly related to natural geographical conditions (e.g., topography, climate, etc.), regional planning (e.g., park layouts, the demarcation of nature reserves), and other socioeconomic factors (Luo et al. 2020; Sun et al. 2020; Yang et al. 2019). In addition, barren lands had no obvious scaling relations, as its area within the three highly urbanized agglomerations was exceedingly small.

Among all LULC types, developed land and cropland were the most predictable at three urban hierarchical levels (Table 3). Developed land and cropland were most severely affected by human activities, especially in urban centers (d'Amour et al. 2016). Socioeconomic factors such as population agglomeration and gross domestic product growth predominantly affect the spatial pattern of developed land and cropland (Arcaute et al. 2015; Gu 2019; Li et al. 2017). The scaling relations of socioeconomic factors can be well approximated by common laws. For example, since the population density and the Gross Domestic Product followed predictable functions in the three urban agglomerations (Fig. A2), the two LULC types were also spatially predictable. The predictable scaling relationships of this study can provide information for the extrapolation of developed lands and croplands at different spatial amplitudes and urban hierarchical levels.

Different urban hierarchical levels presented various scaling relationships for LULC, of which the city proper level was the most predictable. For example, water bodies and barren land showed 
metropolitan and urban agglomeration levels (Table 3). This was predominantly because the influencing factors of LULC distributions became more diverse with the gradual expansion of spatial amplitude (i.e., the addition of more natural, geological, and policy factors, such as topography, climate, and regional planning) (Du et al. 2014; Verburg et al. 2003). This made the scaling relationships more complex and increased unpredictability. At the city proper level, linear relationships (i.e., power law with scaling exponent $=1$ ) existed for most of the LULC types. The results were relatively consistent with those of previous studies, showing that developed lands followed power law scaling relationships with increasing extent in highly urbanized areas (Ma et al. 2019). In urban centers, human production and living activities severely disturbed the land spatial composition. Previous studies have proved that high population densities mainly influenced the spatial patterns of urban developed lands within the city proper (Ma et al. 2016a; Ma et al. 2019). As the spatial extent increased to broader metropolitan and urban hierarchical levels, population densities became smaller and more stable and showed exponential decay functions at the urban agglomeration level (Fig. A2). Thus, human disturbances gradually weakened outside the suburbs (Lan et al. 2021; Liu et al. 2018). This led to the change rates of developed land and cropland slow down and the corresponding regression curves became exponential rules at the broader scales (Fig. 3; Table 3).

Different urban agglomerations also presented various scaling relationships for LULC, among which the relations in BTH were the most predictable and those in YRD were the weakest. This was related to the development modes of urbanization in the agglomerations. BTH was a simple combined urban agglomeration, with Beijing as the core metropolitan area and Tianjin as the sub-core city. PRD contains core cities concentrated in the central region while YRD was a more complex urban agglomeration with several dispersed core cities (Fig. 2) (Fang and Yu 2017). Especially for YRD, the spatial patterns of different LULC presented complex and unpredictable scaling relations. The main reasons were as follows: (1) the city proper of Shanghai can only expand westward due to topography conditional constraints (Fig. 1) and (2) YRD is a spatial polycentric mega-city region (Chen et al. 2019), which led to the fragmentation of forest, croplands, and other landscape patches ( $\mathrm{Lu}$ et al. 2018). This kind of polycentric pattern was induced by a series of regional integration development measures. For example, the General Office of the State Council, PRC, proposed the "Regional Plan for Yangtze River Delta Region" in 2010 (www.gov.cn/) and implemented equal infrastructure construction, industrial planning, and public service popularization in each core city, which aggravated polycentric development.

How did the scaling relations of multiple ESs change and response to LULC across different urban hierarchical levels and agglomerations?

Most ES values increased with the increasing spatial extent, except for water yield, nitrogen retention, and soil retention in three urban agglomerations. The average values of carbon storage, $\mathrm{PM}_{2.5}$ removal, habitat quality, and recreational opportunity were lower in urban centers and 
414 became higher in broader metropolitan and urban agglomeration regions, due to the increase of 415 ecological lands, such as forests, wetlands, and grasslands (Fig. 2). Previous studies have shown 416 that ecological land per unit can provide more similar regulation and cultural services, compared 417 to artificial land (Baumeister et al. 2020; Luo et al. 2018). In contrast, the values of water yield 418 were highest in urban centers. This was mainly because the reference evapotranspiration in urban 419 areas was less than in suburban vegetated areas (Benra et al. 2021; Yang et al. 2019). It is worth 420 noting that soil retention changed irregularly with increase in spatial extent. The phenomenon was 421 largely determined by comprehensive factors, such as topography (Sun et al. 2014), rainfall 422 intensity (Rodríguez-Caballero et al. 2013), and vegetation distribution (Korkanç and Dorum 423 2019).

424 For different types of ESs, provisioning services were most predictable. The food production 425 and water yield showed predictable scaling relations at all hierarchical levels and urban 426 agglomerations. For example, food production revealed power law and exponential growth 427 relationships at all three urban agglomerations. Landscape structure (e.g., composition and 428 configuration) was often considered linked to ecological processes and ESs (Botequillha Leitao 429 and Ahern 2002). To be specific, the scaling relations of food production in this study might be 430 associated with the predictable distribution of croplands. Both food production and croplands 431 increased rapidly on smaller scales (power law functions) and became stable at larger urban 432 agglomeration scales (exponential functions). In addition, some types of regulating ESs only 433 exhibited predictable functions at certain urban levels, such as for carbon storage and $\mathrm{PM}_{2.5}$ 434 removal within YRD (Fig. 7). When the spatial scale extended to the broader urban hierarchical 435 levels, the scaling relationships of these two indicators transformed into complex staircase-like 436 patterns. A previous study has shown that the scalograms of urban impervious surfaces exhibited 437 scale breaks (change points) that corresponded roughly to the urban administrative levels (Wu and 438 Li 2006). Similar to urban impervious surfaces, the breakpoint changes also existed in croplands, 439 forests, and developed lands (Fig. 3f), which might cause the staircase-like patterns of carbon 440 storage and $\mathrm{PM}_{2.5}$ removal within YRD.

441 Different urban hierarchical levels presented two types of scaling functions for ESs, among 442 which the power laws predominantly expressed ES patterns at smaller levels while exponential 443 relationships were more suitable for larger levels. Although the power law function was found to 444 be ubiquitous when representing the scaling relationship between ecological attributes and 445 measurable scales (Fisher et al. 2008; Newman 2005; Spence 2004), it cannot fully express the 446 scaling results of LULC and ESs for various types and urban hierarchical levels. Zhao and Liu 447 (2014) found that a similar power law relationship existed in the critical scale resolution of the 448 carbon cycle with spatial extent. They proposed that future studies should further investigate the 449 compatibility of power law with the scaling relations of ecological indicators. This study fills the 450 research gap in the scaling of ESs and demonstrates that power law scaling can be fitted well only 451 at certain ranges or urban hierarchical levels. At the city proper level, landscape structures were 
often shaped by anthropogenic factors that were related to developed lands, such as demographic, economic, and traffic (Li et al. 2013; Ma et al. 2019; Xie et al. 2017). Consequently, the ESs revealed similar predictable power law functions that were consistent with developed lands. As the spatial extent increased to broader metropolitan or urban agglomeration regions, cropland, forest, and other ecological lands were incorporated into dominant LULC types (Fig. 3). Natural factors, such as topography and climate conditions, which are macroscopic and stable, became the main driving forces in shaping landscape patterns and processes (Peng et al. 2017; Smith et al. 2019). Thus, the ES patterns became stable and exhibited significant exponential relationships on a broader scale.

Different urban agglomerations also presented various scaling relationships for ESs, among which the BTH was the most quantitatively predictable while the YRD was unpredictable. The study showed that the more complicated the distribution of LULC, the greater the variability of ES patterns (Yee et al. 2021) and the poorer the predictability of scaling relations. Therefore, the predictability of spatial scaling of ESs may be closely related to the complexity of LULC patterns. Compared with YRD and PRD, the distribution shape of BTH was more regular and the LULC area was spread evenly in all directions of concentric circles (Fig. 1). The urbanization of BTH was dominated by the "urban edge-expansion mode (the newly developed patches expanded from the fringes of existing urban centers)" (Jia et al. 2020), which made ESs more scale-predictable. However, the scaling relations of ESs in YRD were difficult to predict for the following two key reasons: (1) the topographical constraints and polycentric urban development had complicated the urban shape and increased landscape fragmentation (Li and Zhou 2019; Tao et al. 2020), and thus intensified the spatial heterogeneity of ESs. (2) Large proportions of ESs were provided by forest and water bodies in YRD; however, these two LULC types were unpredictable (Table 3), which also affected the predictability of spatial scaling of ESs.

\section{How to integrate the scaling relations of ESs into land use planning and policy practice?}

The results of this study confirmed that the scaling of ESs were closely related to the land use patterns in urban agglomerations. Thus, the supply of multiple ESs can be effectively improved by managing the spatial patterns of LULC (Mitchell et al. 2015). The most vulnerable and the worst performing area for multiple ESs was the city proper, the key human dominated region (Robinson et al. 2009). It thus required land use optimization. At the city proper level, LULC patterns were more predictable, and thus, the planning can promote ESs more predictably. However, urbanization expansion and LULC spatial patterns emerged from a myriad of policy decisions and planning processes (Batty 2008). To conserve ESs, diversified land management measures should be implemented to avoid disorderly or leapfrog urban expansion. First, more compact urban expansion forms should be encouraged, such as improving land use efficiency to maintain rational densification (Shoemaker et al. 2019; Wang et al. 2019a). Second, conserving the natural land cover, such as by setting the "ecological red line" to protect green and blue spaces in urban areas 
(Lin and Li 2019), can effectively improve regulating and cultural services. Specifically, the priorities are to reconcile the conflict between developed land and cropland in the city proper of Beijing while protecting those ecological lands that are affected by urbanization most seriously, such as water bodies in the city proper of Shanghai and forests in the city proper of Guangzhou (Fig. 3) (Wang et al. 2020; Zhang et al. 2020a). Third, decision-makers can adjust landscape structures by optimizing landscape configuration (Rieb and Bennett 2020), promoting landscape connectivity, and using other measures to support the landscape multifunctionality (Bolliger et al. 2011) and increase the supply of ESs per unit area.

The scaling relations of ESs could reflect the actual spatial characteristics of the ecological environment at each urban hierarchical level of the urban agglomerations. We used piecewise function to simulate the scaling curve of ESs, which can reflect the critical thresholds (change points) of various ES indicators (Momblanch et al. 2016) that were the turning points of the change rates of scaling relations for ESs (Fig. 10a). The range of change point represents the actual geographical boundary of the ES scaling changes, which was not consistent with the urban administrative boundary. Fig. 10b and Fig. 10c illustrate the distance (variance) between the change point of ES scaling relations and the administrative boundary for multiple ESs in the three urban agglomerations. In the city proper, the change point values for most of the ESs were larger than the boundary value of the city proper of Beijing, while the change point values for all ESs were less than the boundary value of the city proper of Guangzhou. This reflected that the eco-environmental effects of urbanization of Beijing city proper had gone beyond the scale of administrative planning, and hence, the actual management extent of ESs should be broader than the administrative boundary. In contrast, the eco-environmental effects of urbanization for Guangzhou city proper had not extended to the administrative boundary, and the actual impact extent of ESs were smaller than the administrative boundary. At the metropolitan level, the actual impact extent of most of the ESs was broader than the administrative boundary in the Shanghai metropolitan region, while the actual ES boundaries were smaller in the Beijing and Guangzhou metropolitan regions. The urban sprawl and polycentric development in the Shanghai metropolitan region (Tao et al. 2020) had exceeded the administrative boundary. Therefore, the Shanghai metropolitan region should pay more attention to the impacts of urbanization on ESs. To effectively protect the ecological environment and natural resources, policy makers should incorporate the actual extent of ES management into sustainable land use planning, rather than merely relying on administrative boundaries (Brunet et al. 2018; Hein et al. 2006). This means that the proposed ES boundary changes can provide a theoretical basis for the boundary determination of the actual natural resource management and landscape planning in urban agglomerations. 

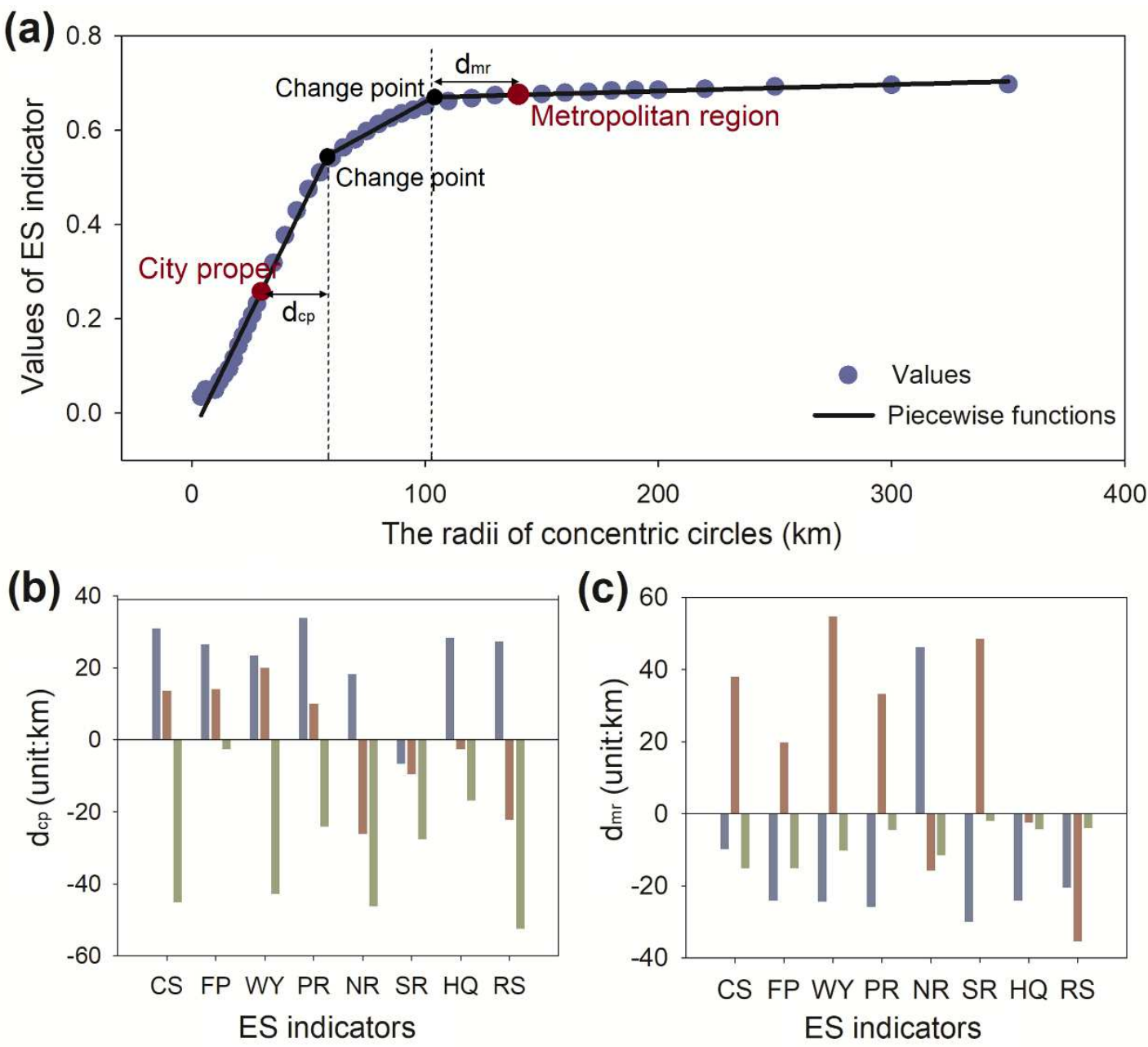

Fig. 10 (a) Example of a scalogram for ecosystem service (ES) change points versus the administrative boundary points. The solid black dots represent the turning points for the ES change rates; the solid red dots represent the administrative boundary points. The " $\mathrm{d}_{\mathrm{cp}}$ " represents the distance between the first change point of ES scaling relations and the administrative boundary of the city proper; the " $\mathrm{d}_{\mathrm{mr}}$ " represents the distance between the second change point of ES scaling relations and the administrative boundary of the metropolitan region. Distance was calculated by the change point value minus the administrative boundary value. (b) The " $\mathrm{d}_{\mathrm{cp}}$ " for multiple ESs in Beijing-Tianjin-Hebei (BTH), Yangtze River Delta (YRD), and Pearl River Delta (PRD) urban agglomerations. $\mathrm{CS}=$ carbon storage; $\mathrm{FP}=$ food production; $\mathrm{WY}=$ water yield; $\mathrm{PR}=\mathrm{PM}_{2.5}$ removal; $\mathrm{NR}=$ nitrogen retention; $\mathrm{SR}=$ soil retention; $\mathrm{HQ}=$ habitat quality; $\mathrm{RS}=$ recreational opportunity. (c) The " $\mathrm{d}_{\mathrm{mr}}$ " for multiple ESs in BTH, YRD, and PRD urban agglomerations.

Limitations and future perspectives

Although the InVEST models contain uncertainties and do not fully reflect the actual indicator values (Daneshi et al. 2021; Pickard et al. 2017), previous studies have confirmed that they performed well in certain regions, which included urbanization areas similar to the ones in the 
current study (Redhead et al. 2016; Sun et al. 2018). Thus, the results of this study in the three urban agglomerations are relatively reliable. The models have been applied with multiple scales and have proven effective (Bagstad et al. 2018; Grafius et al. 2016; Nelson et al. 2009). Therefore, they could be used in the current study to explore the scaling relations and overall trends and changes of ESs. However, uncertainties still existed in the identification of scaling relationships for LULC and ESs. For example, the predictable scaling relationships for some ES indicators can be characterized by either the power law or the exponential function. The fitting functions were determined solely based on significance ( $\mathrm{P}$ values) and determination coefficient $\left(\mathrm{R}^{2}\right)$ values. Future research should increase the sampled database of urban agglomerations and validate the scaling relations we proposed in this study. This will help in choosing more universal and reasonable regression models and in analyzing the underlying biophysical mechanisms behind them. Besides, previous research mainly focused on exploring how the natural and socio-economic attributes changed with different city scale (where population was usually used as the proxy indicator) (Bettencourt and Lobo 2016; Zhao et al. 2018a). These studies often adopted power law functions to express the relationships between city attributes and scales (Bettencourt 2013; Bettencourt et al. 2010; Wu 2004). In the future, we can compare the fitting curves derived from the scaling relations of the city scale indicator (e.g., population) or the spatial extent, to further understand the scale dependence of urban landscape patterns and ecological processes. In addition, we selected three highly developed national-level urban agglomerations in China to reflect the scaling relations of multiple LULC types and ESs. Previous study proved that the scaling relations of developed land in other six world metropolitan regions were closely resembled those of Beijing, Shanghai, and Guangzhou (Ma et al. 2019). In the future study, it still needs to be demonstrated whether the scaling relations of different LULC types and ESs would hold in urban agglomerations with other development levels in China or other countries.

\section{Conclusions}

Exploring how LULC and ES patterns change spatially across multiple scales is helpful for promoting urban landscape sustainability. Based on LULC maps and ES assessment results, this study used the scalogram forms to explore how different LULC types and ES indicators respond to changing spatial extents in the three largest urban agglomerations of China. The results revealed that different LULC mainly exhibited three types of scaling relations, linear, exponential, and sigmoidal relationships, among which developed land and cropland were the most predictable. LULC types at the city proper level were more predictable than the metropolitan and urban agglomeration levels. Most of the ES indicators increased when the spatial extent increased, but their scaling relations varied; provisioning services were the most predictable, while soil retention was unpredictable. The ESs predominantly presented two types of scaling functions, among which power law expressed ES patterns mainly at the lower levels while the exponential relationships were applicable to the higher levels. Among the three urban agglomerations, BTH performed the 
best, while YRD performed the worst in the predictability of the ES spatial scaling. Since the scaling relations of ESs were deeply affected by the LULC patterns, implementing land use composition and configuring optimization strategies are conducive to ecological conservation planning, especially in the city proper. The scaling relations of ESs can provide a scientific basis for the boundary determination of urban land use management.

\section{Acknowledgements}

This work was supported by the National Natural Science Foundation of China [Grant No. 41901227 and U1901601], the Open Foundation of the State Key Laboratory of Urban and Regional Ecology of China [Grant No. SKLURE2020-2-1], and the Fundamental Research Funds for Central Non-profit Scientific Institution [Grant No. 1610132021001].

\section{Declarations}

Conflict of interest The authors declare that they have no conflict of interest.

\section{References}

Arcaute E, Hatna E, Ferguson P, Youn H, Johansson A, Batty M (2015) Constructing cities, deconstructing scaling laws. J R Soc Interface 12(102): 20140745

Bagstad KJ, Cohen E, Ancona ZH, McNulty SG, Sun G (2018) The sensitivity of ecosystem service models to choices of input data and spatial resolution. Appl Geogr 93: 25-36

Batty M (2008) The size, scale, and shape of cities. Science 319(5864): 769-771

Baumeister CF, Baumeister T, Plieninger T, Schraml U (2020) Exploring cultural ecosystem service hotspots: Linking multiple urban forest features with public participation mapping data. Urban For Urban Gree 48: 126561

Benra F, Frutos AD, Gaglio M, Álvarez-Garretón C, Felipe-Lucia M, Bonn A (2021) Mapping water ecosystem services: Evaluating InVEST model predictions in data scarce regions. Environ Modell Softw 3: 104982

Bettencourt LM (2013) The origins of scaling in cities. Science 340(6139): 1438-1441

Bettencourt LM, Lobo J (2016) Urban scaling in Europe. J R Soc Interface 13(116): 20160005

Bettencourt LM, Lobo J, Helbing D, Kühnert C, West GB (2007) Growth, innovation, scaling, and the pace of life in cities. Proc Natl Acad Sci USA 104(17): 7301-7306

Bettencourt LM, Lobo J, Strumsky D, West GB (2010) Urban scaling and its deviations: revealing the structure of wealth, innovation and crime across cities. PLoS One 5: e13541

Bian H, Gao J, Wu J, Sun X, Du Y (2020) Hierarchical analysis of landscape urbanization and its impacts on regional sustainability: A case study of the Yangtze River Economic Belt of China. 
Bolliger J, Bättig MB, Gallati J, Kläy A, Stauffacher M, Kienast F (2011) Landscape multifunctionality: a powerful concept to identify effects of environmental change. Reg Environ Change 11: 203-206

Leitão AB, Ahern J (2002) Applying landscape ecological concepts and metrics in sustainable landscape planning. Landsc Urban Plan 59:65-93

Brock WA (1999) Scaling in economics: a reader's guide. Ind Corp Change 8(3): 409-446

Brunet L, Tuomisaari J, Lavorel S, Crouzat E, Bierry A, Peltola T, Arpin I (2018) Actionable knowledge for land use planning: Making ecosystem services operational. Land Use Policy 72: $27-34$

Chen G, Li X, Liu X, Chen Y, Liang X, Leng J, Xu X, Liao W, Qiu Y, Wu Q, Huang K (2020) Global projections of future urban land expansion under shared socioeconomic pathways. Nat Commun 11: 1-12

Chen W, Yenneti K, We YD, Yuan F, Wu JW, Gao JL (2019) Polycentricity in the Yangtze River Delta Urban Agglomeration (YRDUA): More Cohesion or More Disparities? Sustainability 11: 3106

Daneshi A, Brouwer R, Najafinejad A, Panahi M, Zarandian A, Maghsood FF (2021) Modelling the impacts of climate and land use change on water security in a semi-arid forested watershed using InVEST. J Hydrol 593: 125621

D’Amour C, Reitsma F, Baiocchi G, Barthel S, Güneralp B, Erb K, Haberl H, Creutzig F, Seto KC (2016) Future urban land expansion and implications for global croplands. Proc Natl Acad Sci USA 114 (34): 8939-8944

Department of Urban Surveys of National Bureau of Statistics of China (DUSNB) (2018) China city statistics yearbook 2019. China Statistics Press, Beijing (in Chinese)

Du S, Wang Q, Guo L (2014) Spatially varying relationships between land-cover change and driving factors at multiple sampling scales. J Environ Manage 137: 101-110

Du Y, Sun T, Peng J, Fang K, Liu Y, Yang Y, Wang Y (2018) Direct and spillover effects of urbanization on $\mathrm{PM}_{2.5}$ concentrations in China's top three urban agglomerations. J Clean Prod 190: $72-83$

Fang C, Yu D (2017) Urban agglomeration: An evolving concept of an emerging phenomenon. Landscape Urban Plan 162: 126-136

Fisher JI, Hurtt GC, Thomas RQ, Chambers JQ (2008) Clustered disturbances lead to bias in large-scale estimates based on forest sample plots. Ecol Lett 11: 554-563

Forgione HM, Pregitzer CC, Charlop-Powers S, Gunther B (2016) Advancing urban ecosystem governance in New York City: Shifting towards a unified perspective for conservation management. Environ Sci Pol 62: 127-132

Frazier AE (2016) Surface metrics: scaling relationships and downscaling behavior. Landscape Ecol 31: 351-363. 
Fuller RA, Gaston KJ (2009) The scaling of green space coverage in European cities. Biol Lett 5(3): 352-355

Gao J, Yu ZW, Wang LC, Vejre H (2019) Suitability of regional development based on ecosystem service benefits and losses: A case study of the Yangtze River Delta urban agglomeration, China. Ecol Indic 107: 105579

Goldstein JH, Caldarone G, Duarte TK, Ennaanay D, Hannahs N, Mendoza G, Polasky S, Wolny S, Daily GC (2012) Integrating ecosystem-service tradeoffs into land-use decisions. P Natl Acad Sci USA 109(19): 7565-7570

Grafius DR, Corstanje R, Warren PH, Evans KL, Hancock S, Harris JA (2016) The impact of land use/land cover scale on modelling urban ecosystem services. Landscape Ecol 31: 1509-1522

Gu C (2019) Urbanization: Processes and driving forces. Sci China Earth Sci 62(9): 1351-1360

Hamel P, Chaplin-Kramer R, Sim S, Mueller C (2015) A new approach to modeling the sediment retention service (InVEST 3.0): Case study of the Cape Fear catchment, North Carolina, USA. Sci Total Environ 524-525: 166-177

Hasan SS, Zhen L, Miah MG, Ahamed T, Samie A (2020) Impact of land use change on ecosystem services: A review. Environ Dev 34: 100527

Hein L, van Koppen K, de Groot RS, van Ierland EC (2006) Spatial scales, stakeholders and the valuation of ecosystem services. Ecol Econ 57: 209-228

Hu M, Li Z, Wang Y, Jiao M, Li M, Xia B (2019) Spatio-temporal changes in ecosystem service value in response to land-use/cover changes in the Pearl River Delta. Resour Conserv Recy 149: $106-114$

Jomnonkwao S, Uttra S, Ratanavaraha V (2020) Forecasting road traffic deaths in Thailand: applications of Time-Series, curve estimation, multiple linear regression, and path analysis models. Sustainability 12(1): 395

Kedron PJ, Frazier AE, Ovando-Montejo GA, Wang J (2018) Surface metrics for landscape ecology: a comparison of landscape models across ecoregions and scales. Landscape Ecol 33: $1489-1504$.

Korkanç SY, Dorum G (2019) The nutrient and carbon losses of soils from different land cover systems under simulated rainfall conditions. CATENA 172: 203-211

Kuang B, Lu X, Han J, Fan X, Zuo J (2020) How urbanization influence urban land consumption intensity: Evidence from China. Habitat Int 100: 102103

Kuang W (2020a) 70 years of urban expansion across China: trajectory, pattern, and national policies. Sci Bull 65: 1970-1974

Kuang W (2020b) National urban land-use/cover change since the beginning of the $21^{\text {st }}$ century and its policy implications in China. Land Use Policy 97: 104747

Lan T, Shao G, Xu Z, Tang L, Sun L (2021) Measuring urban compactness based on functional characterization and human activity intensity by integrating multiple geospatial data sources. Ecol Indic 121: 107177 
Lan X, Tang H, Liang H (2017) A theoretical framework for researching cultural ecosystem service flows in urban agglomerations. Ecosyst Serv 28: 95-104

Lavorel S, Rey P, Grigulis K, Zawada M, Byczek C (2020) Interactions between outdoor recreation and iconic terrestrial vertebrates in two French alpine national parks. Ecosyst Serv 45: 101155

Lawler J, Lewis D, Nelson E, Plantinga A, Polasky S, Withey J, Helmers D, Martinuzzi S, Pennington D, Radeloff V (2014) Projected land-use change impacts on ecosystem services in the United States. Proc Natl Acad Sci USA 111(20): 7492-7497

Lei J, Wang S, Wu J, Wang J, Xiong X (2021) Land-use configuration has significant impacts on water-related ecosystem services. Ecol Eng 160: 106133

Li C, Li J, Wu J (2013) Quantifying the speed, growth modes, and landscape pattern changes of urbanization: a hierarchical patch dynamics approach. Landscape Ecol 28(10): 1875-1888

Li H, Peng J, Liu Y, Hu Y (2017) Urbanization impact on landscape patterns in Beijing City, China: A spatial heterogeneity perspective. Ecol Indic 82: 50-60

Li W, Hai X, Han L, Mao J, Tian M (2020) Does urbanization intensify regional water scarcity? Evidence and implications from a megaregion of China. J Clean Prod 244: 118592

Li F, Zhou T (2019) Effects of urban form on air quality in China: An analysis based on the spatial autoregressive model. Cities 89: 130-140

Lin JY, Li X (2019) Large-scale ecological red line planning in urban agglomerations using a semi-automatic intelligent zoning method. Sustain Cities Soc 46: 101410

Liu L, Xu X, Chen X (2015) Assessing the impact of urban expansion on potential crop yield in China during 1990-2010. Food Sec 7: 33-43

Liu W, Zhan J, Zhao F, Yan H, Zhang F, Wei X (2019) Impacts of urbanization-induced land-use changes on ecosystem services: A case study of the Pearl River Delta Metropolitan Region, China. Ecol Indic 98: 228-238

Liu Y, Zhang X, Kong X, Wang R, Chen L (2018) Identifying the relationship between urban land expansion and human activities in the Yangtze River Economic Belt, China. Appl Geogr 94: $163-177$

Liu Y, Zhang X, Pan X, Ma X, Tang M (2020) The spatial integration and coordinated industrial development of urban agglomerations in the Yangtze River Economic Belt, China. Cities 104: 102801

Lobo J, Bettencourt LM, Smith ME, Ortman S (2020) Settlement scaling theory: Bridging the study of ancient and contemporary urban systems. Urban Stud 57(4): 731-747

Lu D, Mao W, Yang D, Zhao J, Xu J (2018) Effects of land use and landscape pattern on $\mathrm{PM}_{2.5}$ in Yangtze River Delta, China. Atmos Pollut Res 9(4): 705-713

Luo Q, Zhang X, Li Z, Yang M, Lin Y (2018) The effects of China's Ecological Control Line policy on ecosystem services: The case of Wuhan City. Ecol Indic 93: 292-301

Luo Q, Zhou J, Li Z, Yu B (2020) Spatial differences of ecosystem services and their driving 
factors: A comparation analysis among three urban agglomerations in China's Yangtze River Economic Belt. Sci Total Environ 725: 138452

Ma Q, He C, Wu J (2016) Behind the rapid expansion of urban impervious surfaces in China: Major influencing factors revealed by a hierarchical multiscale analysis. Land Use Policy, 59, 434-445

Ma Q, Wu J, He C (2016b). A hierarchical analysis of the relationship between urban impervious surfaces and land surface temperatures: spatial scale dependence, temporal variations, and bioclimatic modulation. Landscape Ecol 31(5): 1139-1153

Ma Q, Wu J, He C, Hu G (2019) Reprint of "Spatial scaling of urban impervious surfaces across evolving landscapes: From cities to urban regions". Landscape Urban Plan 187: 132-144

Massada AB, Radeloff VC (2010) Two multi-scale contextual approaches for mapping spatial pattern. Landscape Ecol 25: 711-725

Millennium Ecosystem Assessment (2005) Ecosystems and Human Well-Being: Synthesis. Island Press, Washington, DC

Mitchell MGE, Bennett EM, Gonzalez A (2015) Strong and nonlinear effects of fragmentation on ecosystem service provision at multiple scales. Environ Res Lett 10: 094014

Momblanch A, Connor JD, Crossman ND, Paredes-Arquiola J, Andreu J (2016) Using ecosystem services to represent the environment in hydro-economic models. J Hydrol 522: 95-109

Nelson E, Mendoza G, Regetz J, Polasky S, Tallis H, Cameron D, Chan KMA, Daily GC, Goldstein J, Kareiva PM, Lonsdorf E, Naidoo R, Ricketts TH, Shaw M (2009) Modeling multiple ecosystem services, biodiversity conservation, commodity production, and tradeoffs at landscape scales. Front Ecol Environ 7(1): 4-11

Newman MEJ (2005) Power laws, Pareto distributions and Zipf's law. Contemp Phys 46: 323-351

Nikodinoska N, Paletto A, Pastorella F, Granvik M, Franzese PP (2018) Assessing, valuing and mapping ecosystem services at city level: The case of Uppsala (Sweden). Ecol Model 121: 107028

Normile D (2016) China rethinks cities. Science 352(6288): 916-918

O'Neill RV, Deangelis DL, Waide JB, Allen GE (1986) A hierarchical concept of ecosystems. Princeton University Press, New Jersey

Patra S, Sahoo S, Mishra P, Mahapatra SC (2018) Impacts of urbanization on land use/cover changes and its probable implications on local climate and groundwater level. J Urban Manag $7(2): 70-84$

Peng J, Liu Y, Liu Z, Yang Y (2017) Mapping spatial non-stationarity of human-natural factors associated with agricultural landscape multifunctionality in Beijing-Tianjin-Hebei region, China. Agric Ecosyst Environ 246: 221-233

Pickard BR, Berkel DV, Petrasova A, Meentemeyer RK (2017) Forecasts of urbanization scenarios reveal trade-offs between landscape change and ecosystem services. Landscape Ecol 32: 617-634 
Poku-Boansi M (2012) Contextualizing urban growth, urbanisation and travel behaviour in Ghanaian cities. Cities 110: 103083

Redhead JW, Stratford C, Sharps K, Jones L, Ziv G, Clarke D, Oliver TH, Bullock JM (2016) Empirical validation of the InVEST water yield ecosystem service model at a national scale. Sci Total Environ 569-570: 1418-1426

Ribeiro FL, Meirelles J, Netto VM, Neto CR, Baronchelli A (2020) On the relation between transversal and longitudinal scaling in cities. PLoS One 15(5): 1-20

Rieb JT, Bennett EM (2020) Landscape structure as a mediator of ecosystem service interactions. Landscape Ecol 35: 2863-2880

Robinson DT, Brown DG, Currie WS (2009) Modelling carbon storage in highly fragmented and human-dominated landscapes: Linking land-cover patterns and ecosystem models. Ecol Modell 220(9): 1325-1338

Rodríguez-Caballero E, Cantón Y, Chamizo S, Lázaro R, Escudero A (2013) Soil loss and runoff in semiarid ecosystems: a complex interaction between biological soil crusts, micro-topography, and hydrological drivers. Ecosystems 16: 529-546

Seto KC, Reenberg A, Boone CG, Fragkias M, Haase D, Langanke T, Marcotullio P, Munroe DK, Olah B, Simon D (2012) Urban land teleconnections and sustainability. Proc Natl Acad Sci USA 109(20): 7687-7692

Smith P, Adams J, Beerling DJ, Beringer T, Calvin KV, Fuss S, Griscom B, Hagemann N, Kammann C, Kraxner F, Minx JC, Popp A, Renforth P, Luis J, Vicente V, Keesstra S (2019) Land-Management options for greenhouse gas removal and their impacts on ecosystem services and the sustainable development goals. Annu Rev Environ Resour 44: 255-286

Sharp R, Douglass J, Wolny S, Arkema K, Bernhardt J, Bierbower W, Chaumont N, Denu D, Fisher D, Glowinski K, Griffin R, Guannel G, Guerry A, Johnson J, Hamel P, Kennedy C, Kim CK, Lacayo M, Lonsdorf E, Mandle L, Rogers L, Silver J, Toft J, Verutes G, Vogl AL, Wood S, Wyatt K (2020) InVEST 3.8.9.post9+ug.ga009fc0 User's Guide. The Natural Capital Project, Stanford University, University of Minnesota, The Nature Conservancy, and World Wildlife Fund

Shen J, Li S, Liang Z, Liu L, Li D, Wu S (2020) Exploring the heterogeneity and nonlinearity of trade-offs and synergies among ecosystem services bundles in the Beijing-Tianjin-Hebei urban agglomeration. Ecosyst Serv 43: 101103

Shoemaker DA, BenDor TK, Meentemeyer RK (2019) Anticipating trade-offs between urban patterns and ecosystem service production: Scenario analyses of sprawl alternatives for a rapidly urbanizing region. Comput Environ Urban 74: 114-125

Spence AJ (2009) Scaling in biology. Curr Biol CB 19: R57-R61

Stokes EC, Seto KC (2019) Characterizing and measuring urban landscapes for sustainability. Environ Res Lett 14: 045002

Sun W, Shao Q, Liu J, Zhai J (2014) Assessing the effects of land use and topography on soil 
erosion on the Loess Plateau in China. CATENA 121: 151-163

Sun X, Lu ZM, Li F, Crittenden JC (2018) Analyzing spatio-temporal changes and trade-offs to support the supply of multiple ecosystem services in Beijing, China. Ecol Indic 94: 117-129

Sun X, Tan X, Chen K, Song S, Zhu X, Hou D (2020) Quantifying landscape-metrics impacts on urban green-spaces and water-bodies cooling effect: The study of Nanjing, China. Urban For Urban Gree 55: 126838

Swenson JJ, Franklin J (2000) The effects of future urban development on habitat fragmentation in the Santa Monica Mountains. Landscape Ecol 15: 713-730

Tao Y, Zhang Z, Ou WX, Guo J, Pueppke SG (2020) How does urban form influence $\mathrm{PM}_{2.5}$ concentrations: Insights from 350 different-sized cities in the rapidly urbanizing Yangtze River Delta region of China, 1998-2015. Cities 98: 102581

Verburg PH, de Groot WT, Veldkamp AJ (2003) Methodology for Multi-Scale Land-Use Change Modelling: Concepts and Challenges. Global Environmental Change and Land Use. Springer, Dordrecht. https://doi.org/10.1007/978-94-017-0335-2_2

Viglizzo EF, Paruelo JM, Laterra P, Jobbágy EG (2012) Ecosystem service evaluation to support land-use policy. Agr Ecosyst Environ 154: 78-84

Wang LZ, Omrani H, Zhao Z, Francomano D, Li K, Pijanowski B (2019) Analysis on urban densification dynamics and future modes in southeastern Wisconsin, USA. PLoS One 14(3): 0211964

Wang Z, Liang L, Sun Z, Wang X (2019b) Spatiotemporal differentiation and the factors influencing urbanization and ecological environment synergistic effects within the Beijing-Tianjin-Hebei urban agglomeration. J Environ Manage 243: 227-239

Wang Z, Zhang S, Peng Y, Wu C, Lv Y, Xiao K, Zhao J, Qian G (2020) Impact of rapid urbanization on the threshold effect in the relationship between impervious surfaces and water quality in shanghai, China. Environ Pollut 267: 115569

Wu J (1999) Hierarchy and scaling: extrapolating information along a scaling ladder. Can J Remote Sens 25(4): 367-380

Wu J (2004) Effects of changing scale on landscape pattern analysis: scaling relations. Landscape Ecol 19: $125-138$

Wu J, David JL (2002) A spatially explicit hierarchical approach to modeling complex ecological systems: theory and applications. Ecol Model 153(1): 7-26

Wu J, Jenerette GD, Buyantuyev A, Redman CL (2011) Quantifying spatiotemporal patterns of urbanization: The case of the two fastest growing metropolitan regions in the United States. Ecol Complex 8(1): 1-8

Wu J, Li H (2006) Perspectives and methods of scaling. In Wu J, Jones B, Li H, Loucks OL (Eds.). Scaling and uncertainty analysis in ecology. Springer, Dordrecht, pp 17-44

Wu J, Shen WJ, Sun WZ, Tueller PT (2002) Empirical patterns of the effects of changing scale on landscape metrics. Landsc Ecol 17: 761-782 
Wu R, Li Z, Wang S (2020) The varying driving forces of urban land expansion in China: Insights from a spatial-temporal analysis. Sci Total Environ 8: 142591

Xie H, He Y, Xie X (2017) Exploring the factors influencing ecological land change for China's Beijing-Tianjin-Hebei Region using big data. J Clean Prod 142: 677-687

Xing L, Zhu Y, Wang J (2021) Spatial spillover effects of urbanization on ecosystem services value in Chinese cities. Ecol Indic 121: 107028

Xu C, Zhao S, Liu S (2020) Spatial scaling of multiple landscape features in the conterminous United States. Landsc Ecol 35: 223-247

Xu Q, Dong Y, Yang R (2018) Influence of land urbanization on carbon sequestration of urban vegetation: A temporal cooperativity analysis in Guangzhou as an example. Sci Total Environ 635: $26-34$

Yang D, Liu W, Tang L, Chen L, Li X, Xu X (2019) Estimation of water provision service for monsoon catchments of South China: Applicability of the InVEST model. Landscape Urban Plan 182: 133-143

Yang J, Yang J, Luo X, Huang C (2019) Impacts by expansion of human settlements on nature reserves in China. J Environ Manag 248: 109233

Yee SH, Paulukonis E, Simmons C, Russell M, Fulford R, Harwell L, Smith LM (2021) Projecting effects of land use change on human well-being through changes in ecosystem services. Ecol Modell 440: 109358

Yu J, Zhou K, Yang S (2019) Land use efficiency and influencing factors of urban agglomerations in China. Land Use Policy 88: 104143

Zhang D, Huang Q, He C, Wu J (2017) Impacts of urban expansion on ecosystem services in the Beijing-Tianjin-Hebei urban agglomeration, China: A scenario analysis based on the Shared Socioeconomic Pathways. Resour Conserv Recycl 125: 115-130

Zhang Y, Hu Y, Zhuang D (2020a) A highly integrated, expansible, and comprehensive analytical framework for urban ecological land: A case study in Guangzhou, China. J Clean Prod 268: 122360

Zhang P, Kohli D, Sun Q, Zhang Y, Liu S, Sun D (2020b) Remote sensing modeling of urban density dynamics across 36 major cities in China: Fresh insights from hierarchical urbanized space. Landscape Urban Plan 203: 103896

Zhang X, Zhong T, Wang K, Cheng Z (2009) Scaling of impervious surface area and vegetation as indicators to urban land surface temperature using satellite data. Int J Remote Sens 30(4): $841-859$

Zhao S, Liu S (2014) Scale criticality in estimating ecosystem carbon dynamics. Glob Change Biol 20: 2240-2251

Zhao S, Liu S, Xu C, Yuan W, Sun Y, Yan W, Zhao M, Henebry GM, Fang J (2018a) Contemporary Evolution and Scaling of 32 Major Cities in China. Ecol Appl 28(6): 16551668 
877 Zhou D, Tian Y, Jiang G (2018b) Spatio-temporal investigation of the interactive relationship 878 between urbanization and ecosystem services: Case study of the Jingjinji urban 879 agglomeration, China. Ecol Indic 95: 152-164

880 Zhou Y, Chen M, Tang Z, Mei Z (2021) Urbanization, land use change, and carbon emissions: 881 Quantitative assessments for city-level carbon emissions in Beijing-Tianjin-Hebei region. $882 \quad$ Sustain Cities Soc 66: 102701 


\section{Figures}

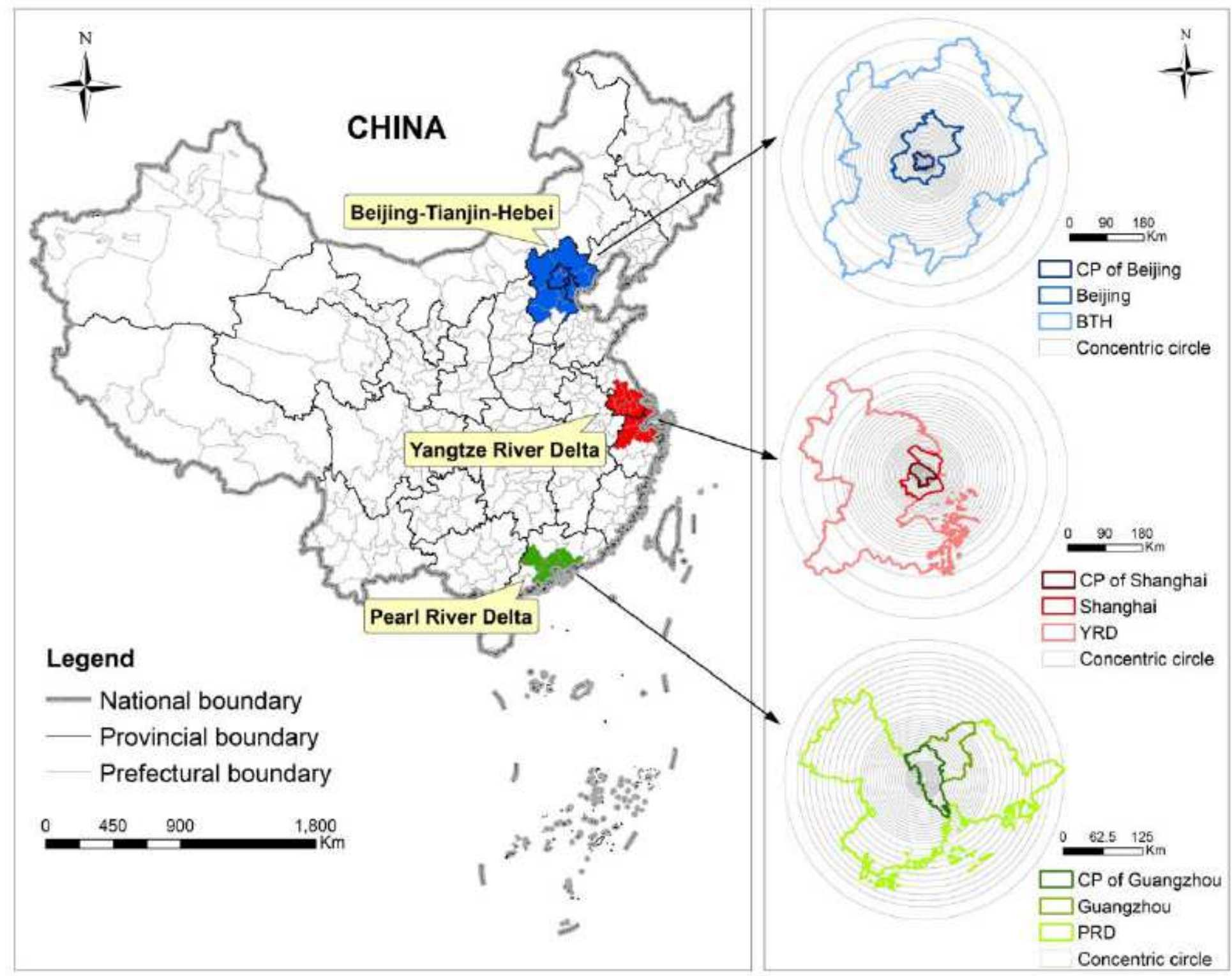

Figure 1

Location and administrative hierarchy of study areas. The concentric circle illustrations on the right represent the spatial extension of three urban agglomerations at the administrative hierarchy levels. The $\mathrm{CP}$ of Beijing/Shanghai/Guangzhou refer to the city proper of Beijing/Shanghai/Guangzhou; Beijing/Shanghai/Guangzhou refer to the Beijing/Shanghai/Guangzhou metropolitan region; BTH/YRD/PRD refer to the Beijing Tianjin Hebei/Yangtze River Delta/Pearl River Delta urban agglomeration. Note: The designations employed and the presentation of the material on this map do not imply the expression of any opinion whatsoever on the part of Research Square concerning the legal status of any country, territory, city or area or of its authorities, or concerning the delimitation of its frontiers or boundaries. This map has been provided by the authors. 
Beijing-Tianjin-Hebei

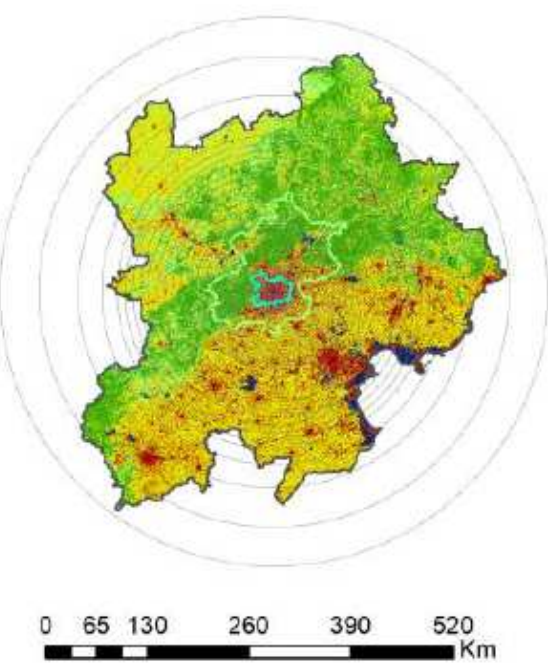

City proper level

Cropland Forest
Yangtze River Delta
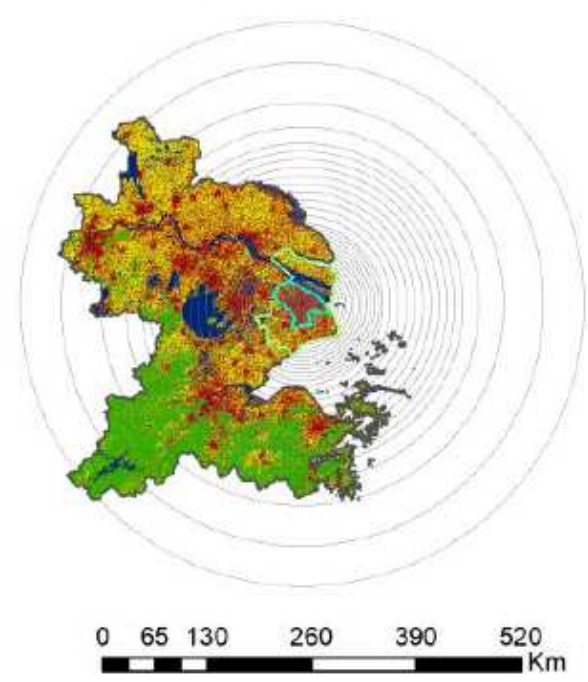

Metropolitan level

Urban agglomeration level

Developed land
Pearl River Delta

$N$
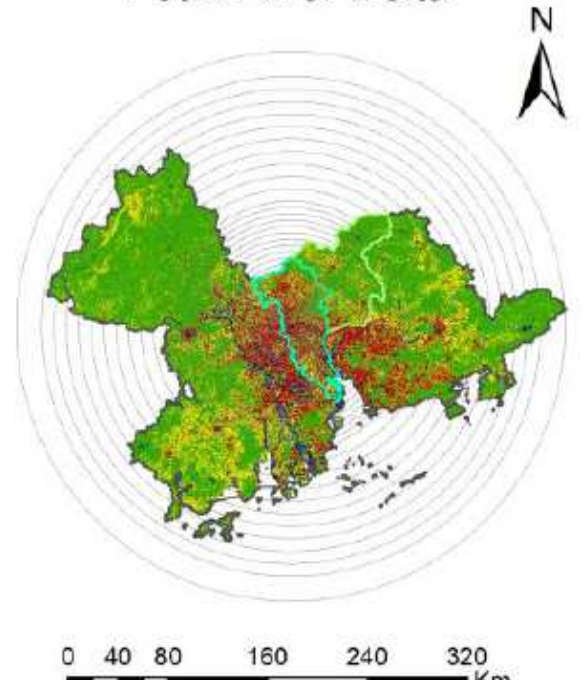

Concentric circle

Barren land

\section{Figure 2}

Spatial distributions of land use/land cover in 2018 for three urban agglomerations. The radii list of concentric circles is shown in Table 2. Note: The designations employed and the presentation of the material on this map do not imply the expression of any opinion whatsoever on the part of Research Square concerning the legal status of any country, territory, city or area or of its authorities, or concerning the delimitation of its frontiers or boundaries. This map has been provided by the authors. 
(a) City proper of Beijing

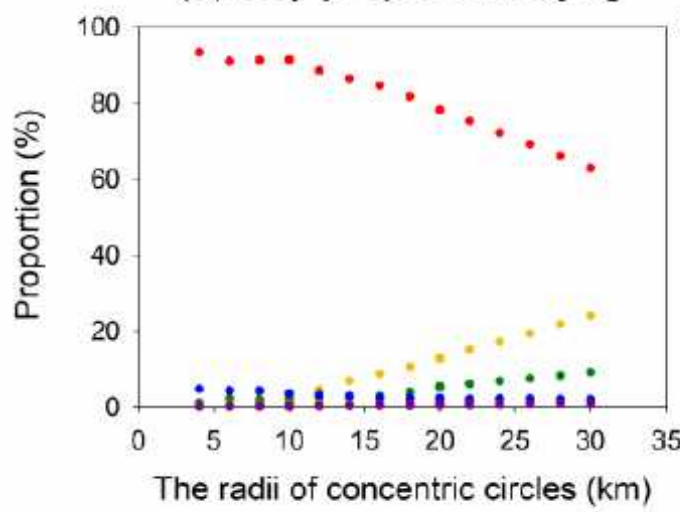

(d) City proper of Shanghai

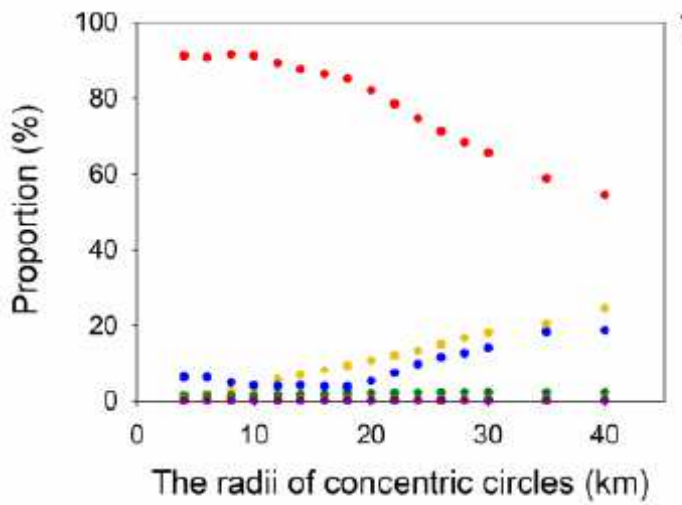

(b) Beijing metropolitan region

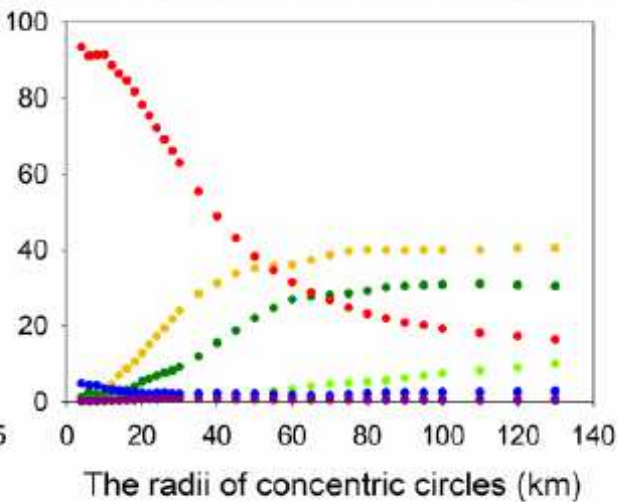

(e) Shanghai metropolitan region

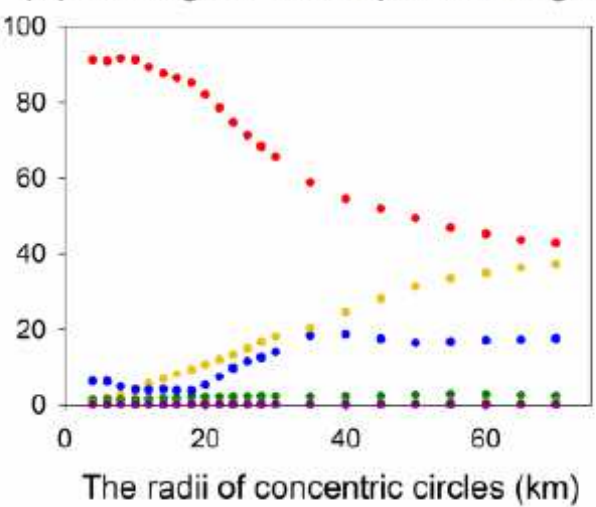

(c) BTH urban agglomeration

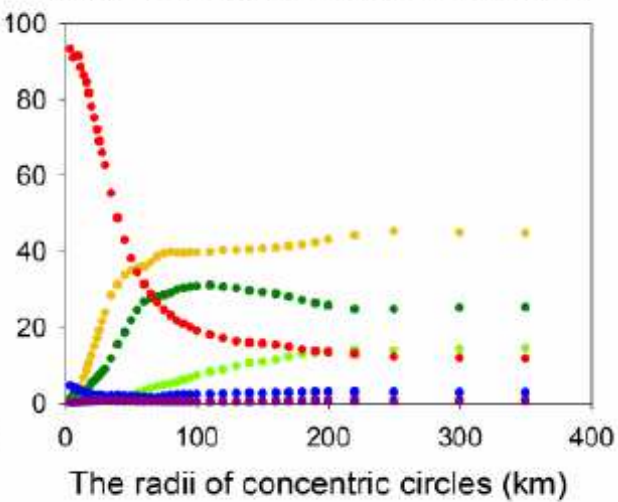

(f) YRD urban agglomeration

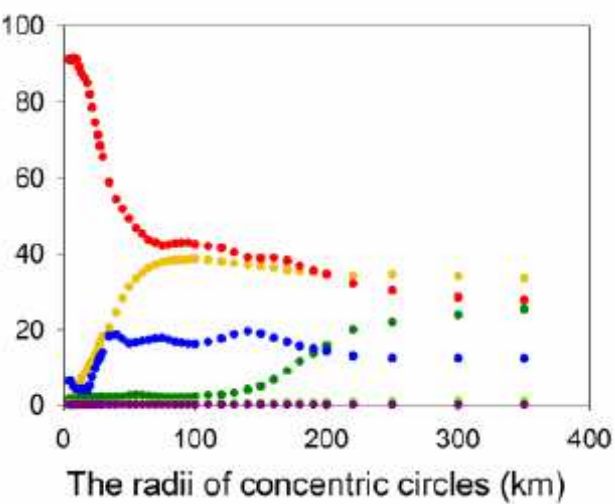

(g) City proper of Guangzhou

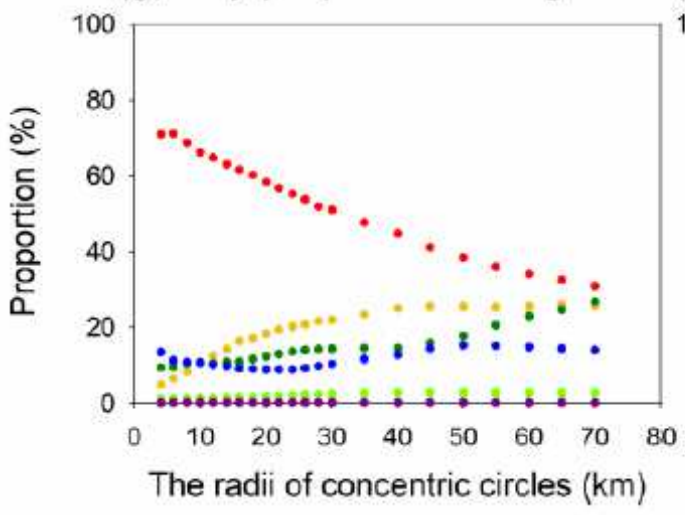

(h) Guangzhou metropolitan region

(i) PRD urban agglomeration
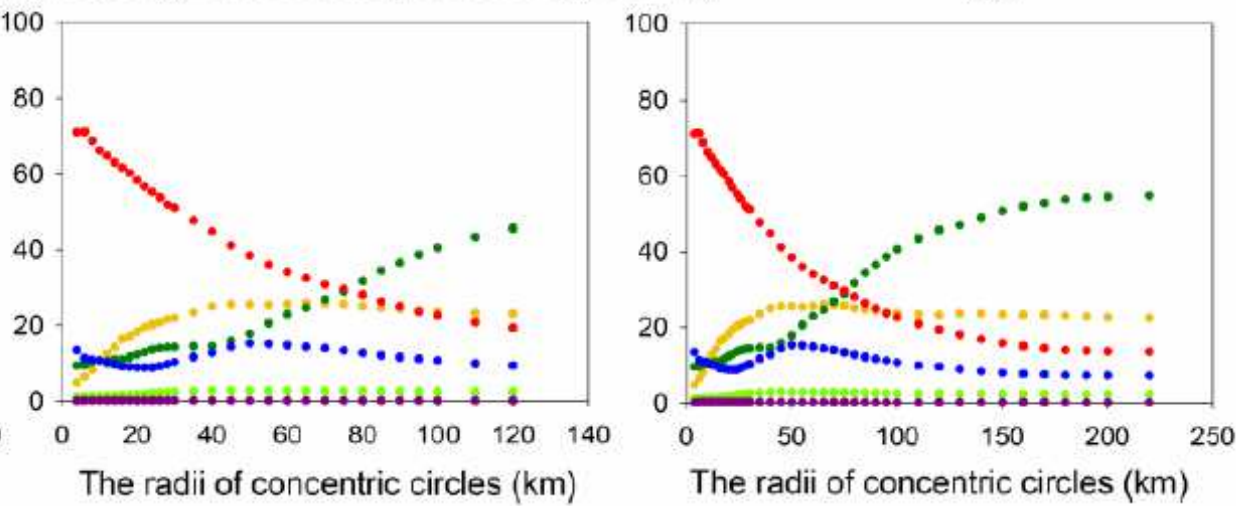

$\begin{array}{lll}\text { - Cropland } & \cdot \text { Grassland } & \cdot \text { Developed land } \\ \text { - Forest } & \cdot \text { Water bodies } & \text { - Barren land }\end{array}$

\section{Figure 3}

Scalograms of the proportion of different land use /land cover types with respect to increasing concentric circle radii in the three largest urban agglomerations of China (Beijing Tianjin Hebei (BTH), Yangtze River Delta (YRD), and Pearl River Delta (PRD)). 


\section{Carbon storage (tons/ha)}

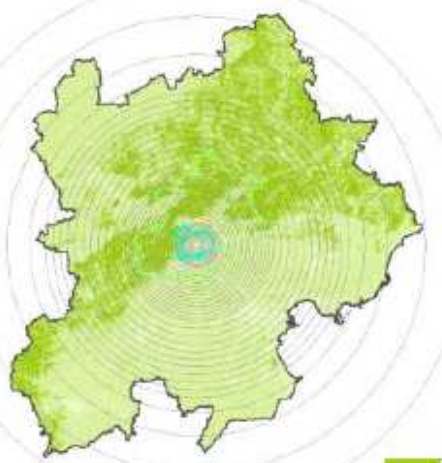

High: 180

Low: 70
Food production (kg/ha)

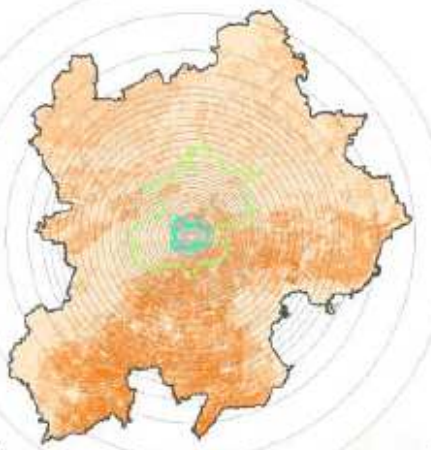

High: 16477

Low: 0
Water yield $(\mathrm{mm})$

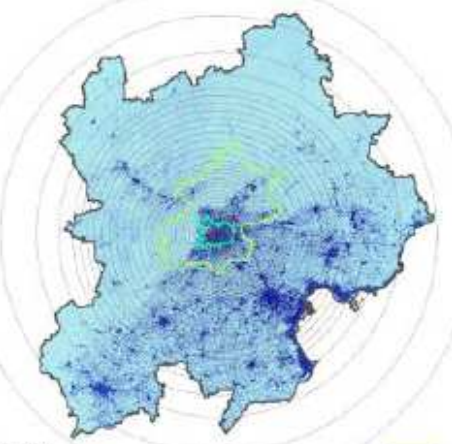

High: 458

Low: 0
PM2.5 removal (kg/ha)

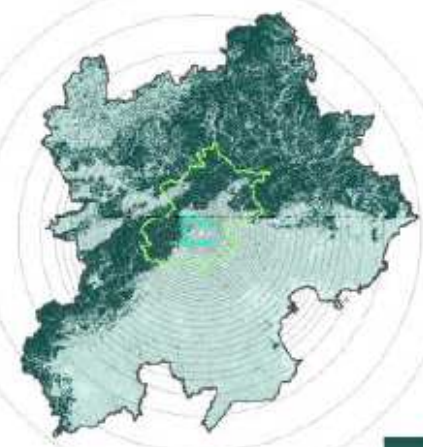

High: 26

Low: 0
Nitrogen retention $(\mathrm{kg} / \mathrm{ha})$

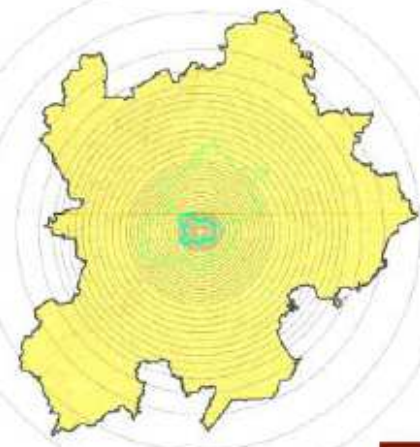

(

Low: 0
Soil retention (tons/ha)

High: 236

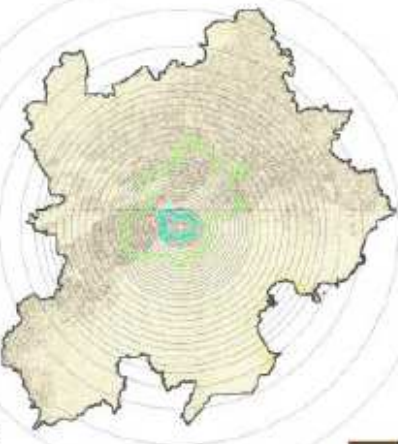

High: 531

Low: 0

Habitat quality index Recreational opportunity index
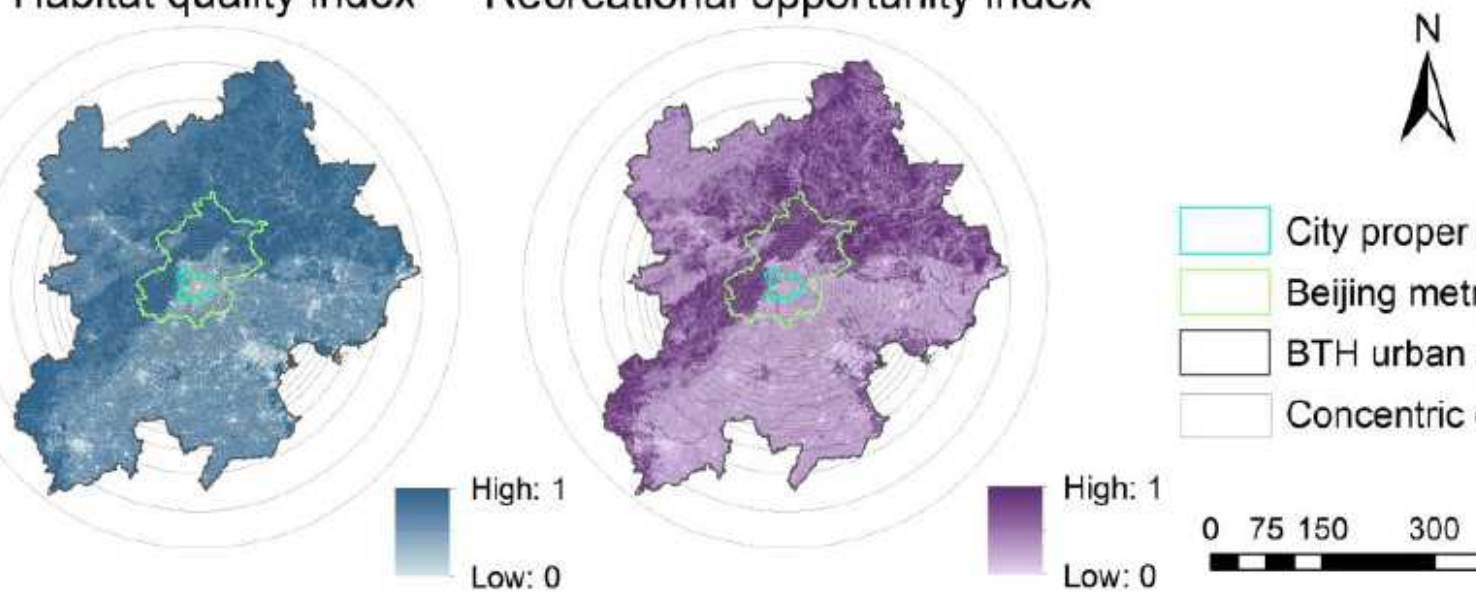

City proper of Beijing Beijing metropolitan region BTH urban agglomeration Concentric circle

High: 1

Low: 0

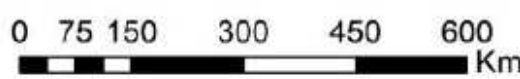

\section{Figure 4}

Spatial distributions of multiple ecosystem services in 2018 for Beijing Tianjin-Hebei (BTH) urban agglomeration. The radii list of concentric circles was shown in Table 2. Note: The designations employed and the presentation of the material on this map do not imply the expression of any opinion whatsoever on the part of Research Square concerning the legal status of any country, territory, city or 
area or of its authorities, or concerning the delimitation of its frontiers or boundaries. This map has been provided by the authors.
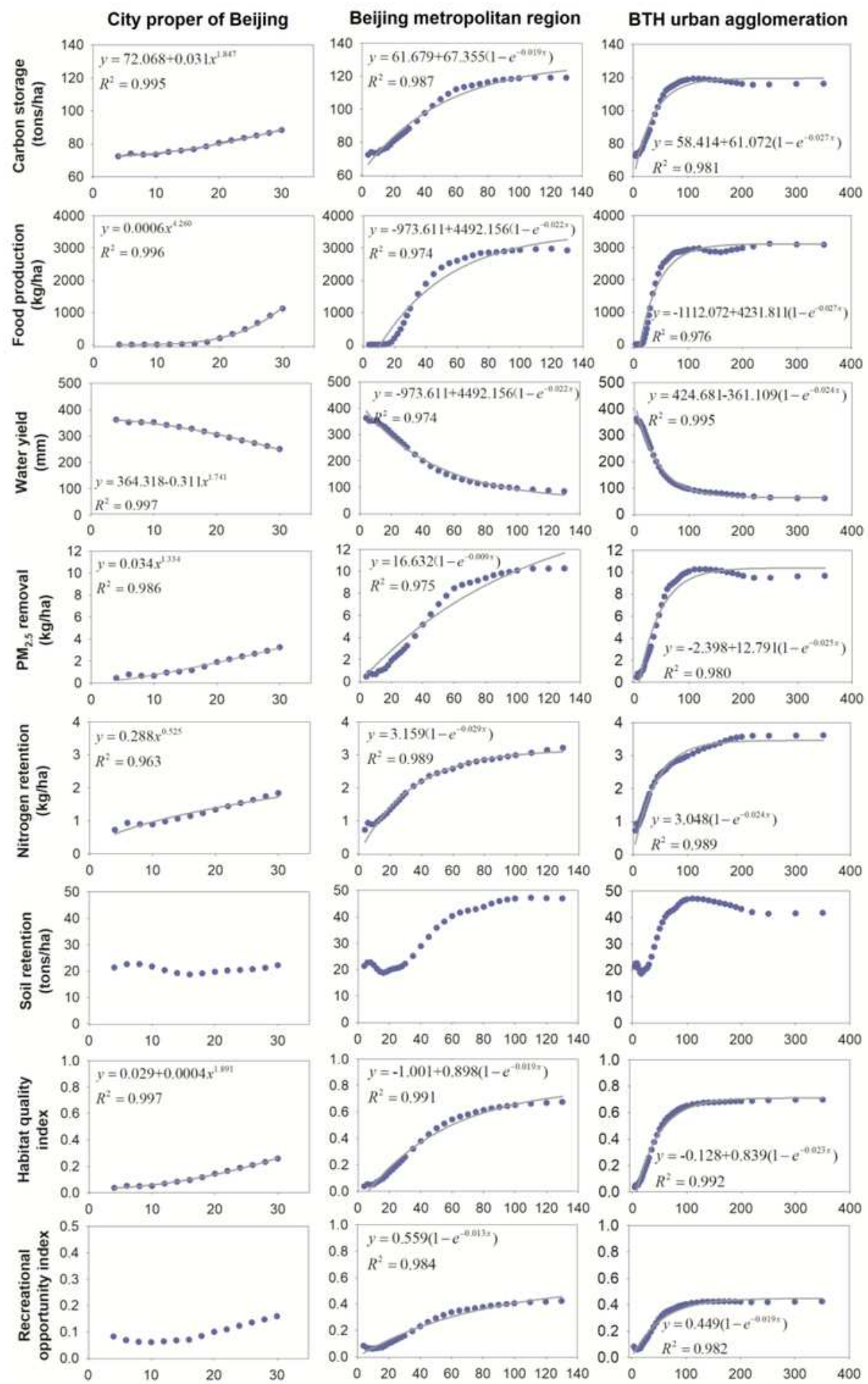

The radii of concentric circles $(\mathrm{km})$ The radii of concentric circles $(\mathrm{km})$ The radii of concentric circles $(\mathrm{km})$

- Ecosystem service values

Regression curve

\section{Figure 5}

Scalograms of multiple ecosystem service indicators with respect to increasing concentric circle radii at various urban hierarchical levels: the city proper of Beijing, Beijing metropolitan region, and the Beijing Tianjin Hebei (BTH). F or all regression curves and equations, the 269 significance level $P$ values $<0.001$. 


\section{Carbon storage (tons/ha) Food production $(\mathrm{kg} / \mathrm{ha}) \quad$ Water yield $(\mathrm{mm})$}
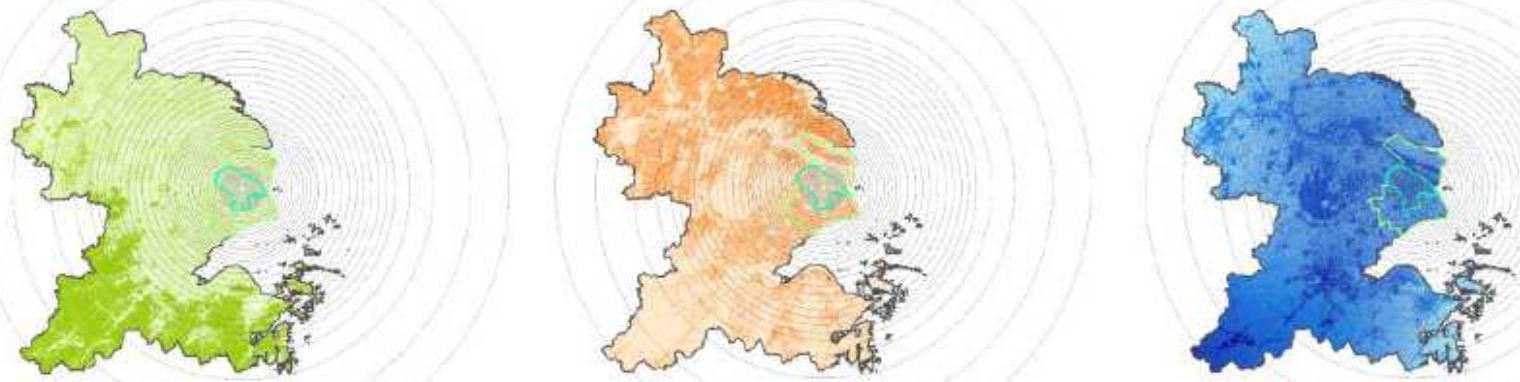

High: 206

High: 19279

High: 2026

Low: 87

Low: 0

Low: 134

$\mathrm{PM} 2.5$ removel $(\mathrm{kg} / \mathrm{ha})$

Nitrogen retention $(\mathrm{kg} / \mathrm{ha})$

Soil retention (tons/ha)
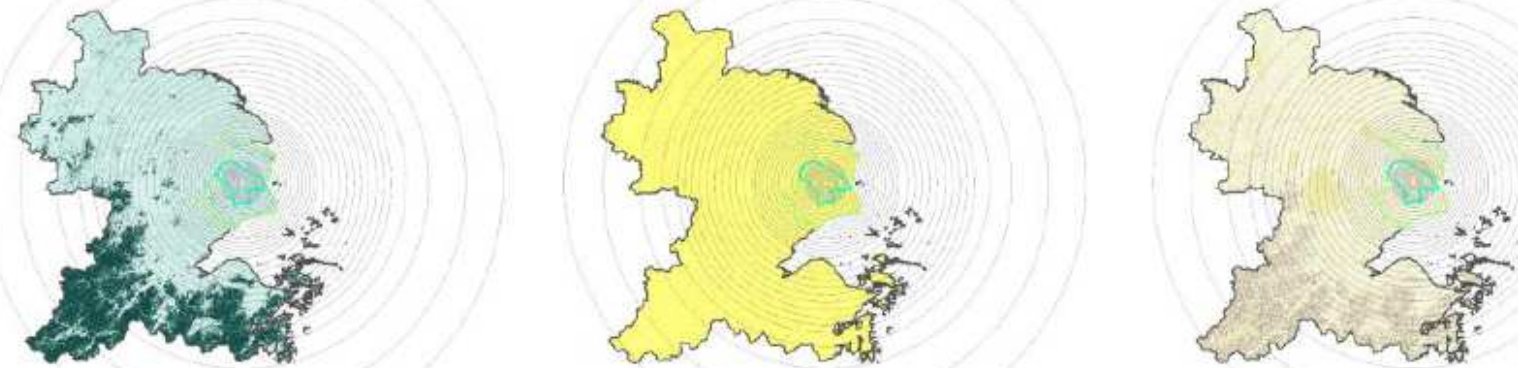

High: 18

High: 251

High: 648

Low: 0

Low: 0

Low: 0

\section{Habitat quality index}

\section{Recreational opportunity index}
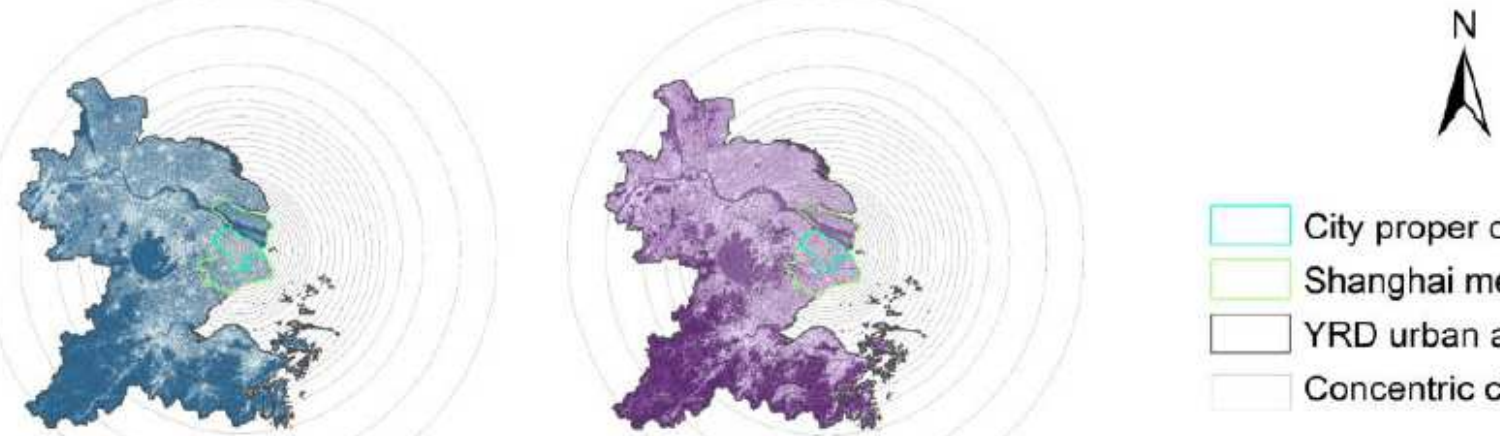

High: 1

High: 1

Low: 0

Low: 0

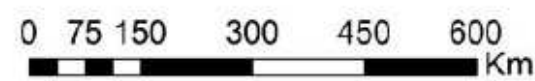

\section{Figure 6}

Spatial distributions of multiple ecosystem services in 2018 for Yangtze River Delta (YRD) urban agglomeration. The radii list of concentric circles was shown in Table 2. Note: The designations employed and the presentation of the material on this map do not imply the expression of any opinion whatsoever on the part of Research Square concerning the legal status of any country, territory, city or 
area or of its authorities, or concerning the delimitation of its frontiers or boundaries. This map has been provided by the authors.
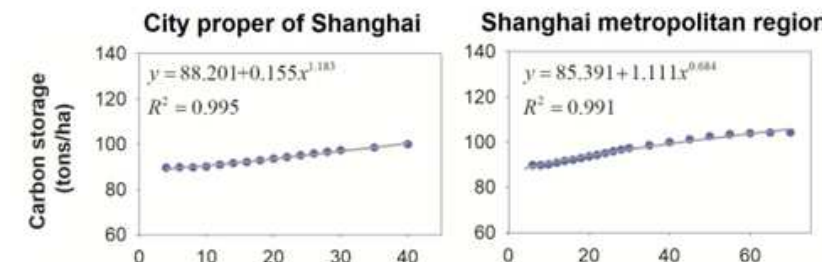

YRD urban agglomeration
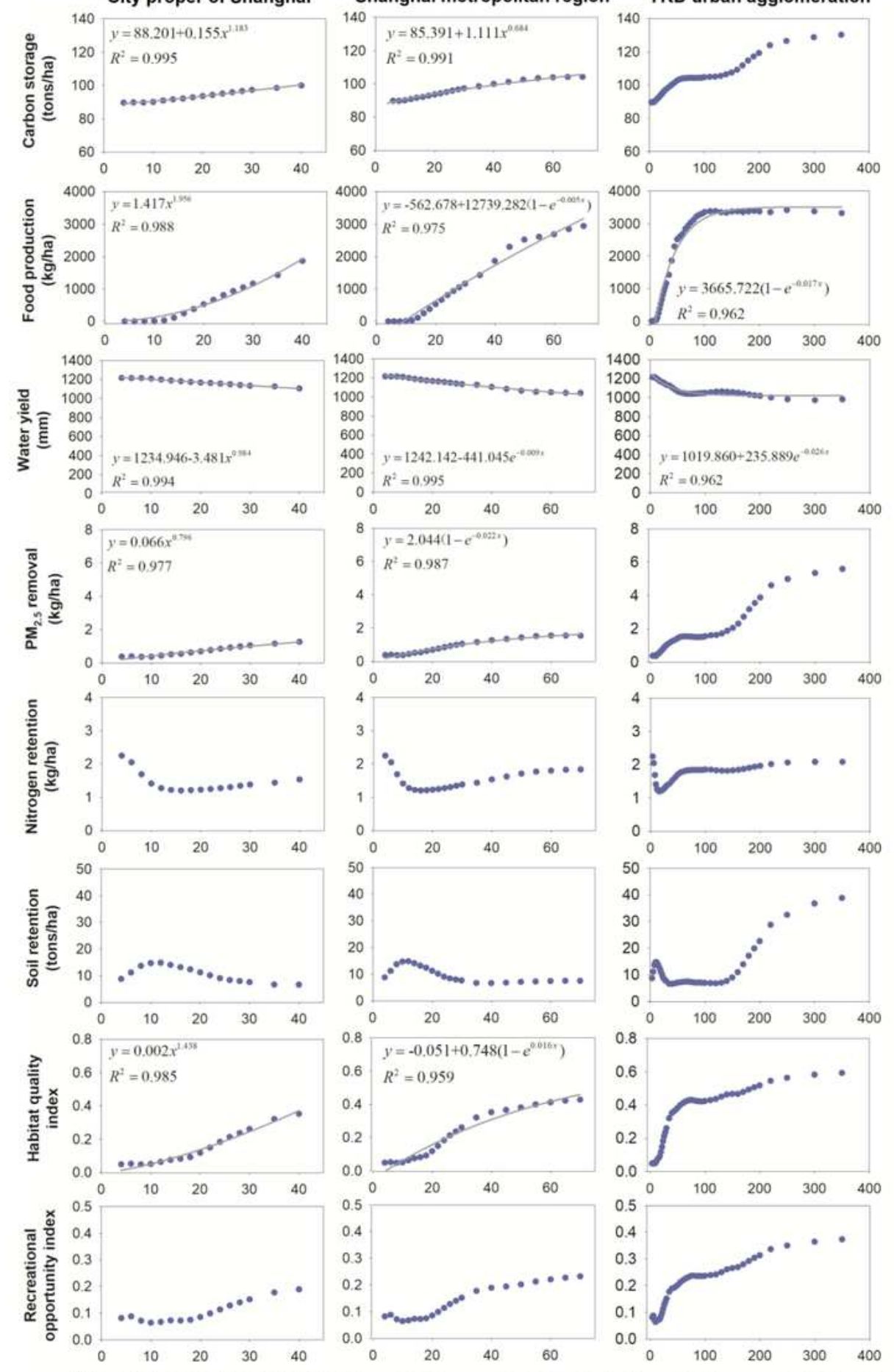

The radii of concentric circles $(\mathrm{km})$ The radii of concentric circles $(\mathrm{km})$ The radii of concentric circles $(\mathrm{km})$

Regression curve

\section{Figure 7}

Scalograms of multiple ecosystem service indicators with respect to increasing concentric circle radii at various urban hierarchical levels: the city proper of Shanghai, Shanghai metropolitan region, and the 
Yangtze River Delta (YRD). For all regression curves and equations, the significance level P values < 0.001 .

Carbon storage (tons/ha) Food production ( $\mathrm{kg} / \mathrm{ha}$ )

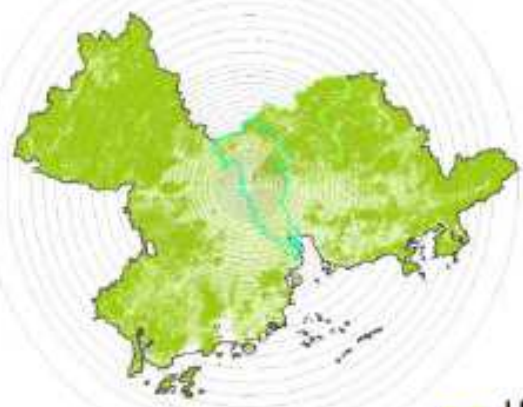

$\mathrm{PM} 2.5$ removel $(\mathrm{kg} / \mathrm{ha})$

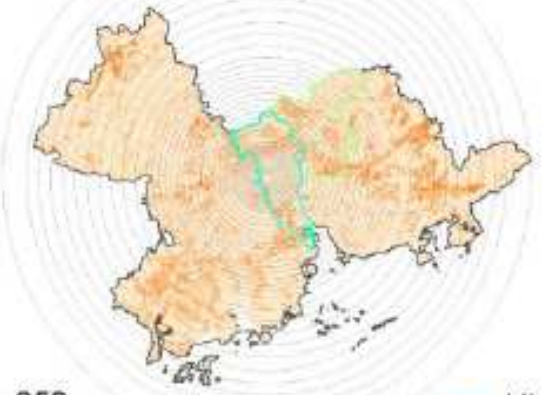

High: 253

Low: 89
Nitrogen retention $(\mathrm{kg} / \mathrm{ha})$
Water yield $(\mathrm{mm})$

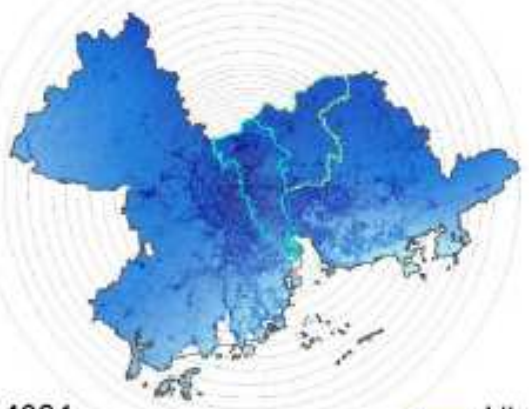

High: 14024 Low: 0
High: 1927 Low: 0

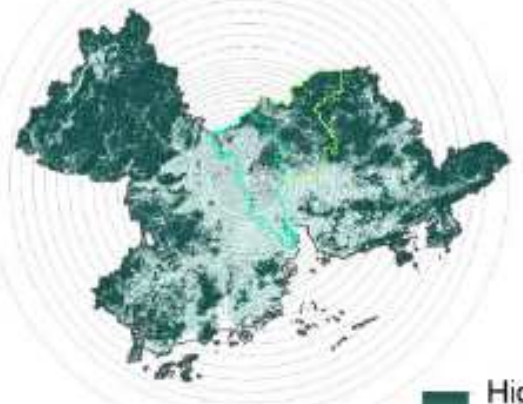

Habitat quality index

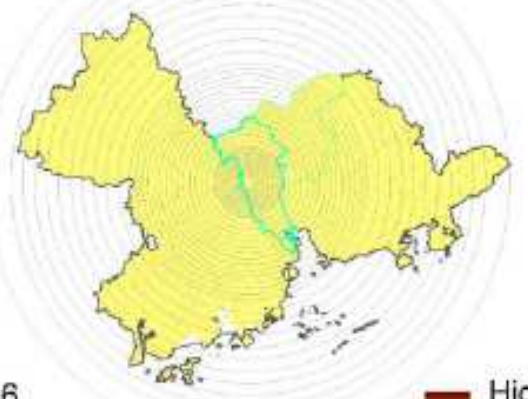

Low: 0

Recreational opportunity index

High: 187

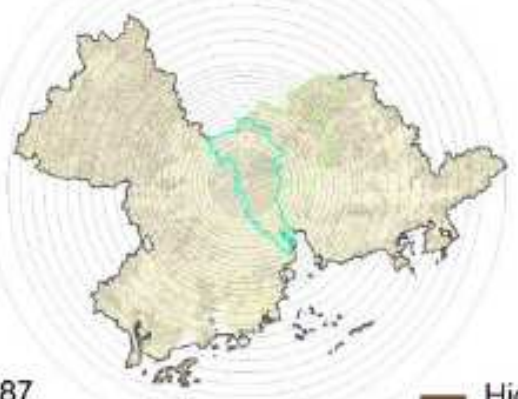

High: 579

Low: 0

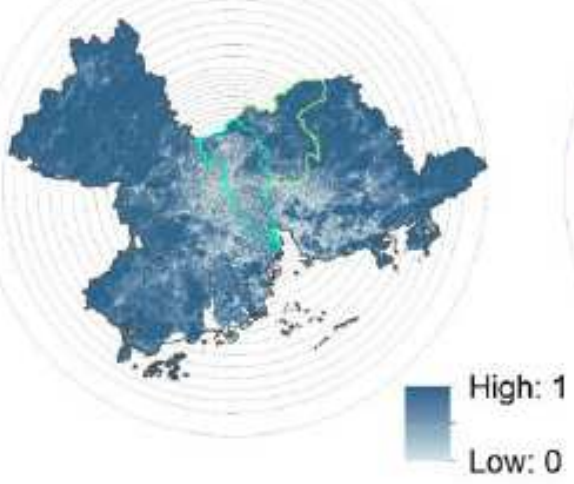

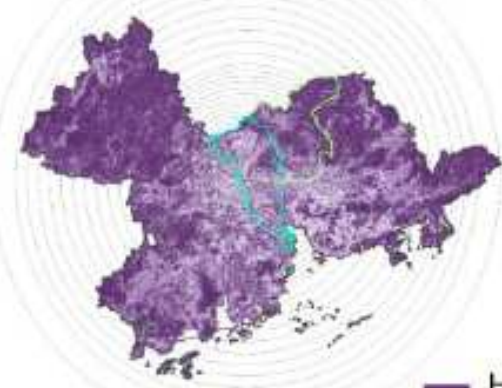

High: 1

Low: 0

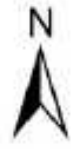

City proper of Guangzhou Guangzhou metropolitan region PRD urban agglomeration Concentric circle

\section{Figure 8}

Spatial distributions of multiple ecosystem services in 2018 for Pearl River Delta (PRD) urban agglomeration. The radii list of concentric circles was shown in Table 2. Note: The designations employed and the presentation of the material on this map do not imply the expression of any opinion 
whatsoever on the part of Research Square concerning the legal status of any country, territory, city or area or of its authorities, or concerning the delimitation of its frontiers or boundaries. This map has been provided by the authors.

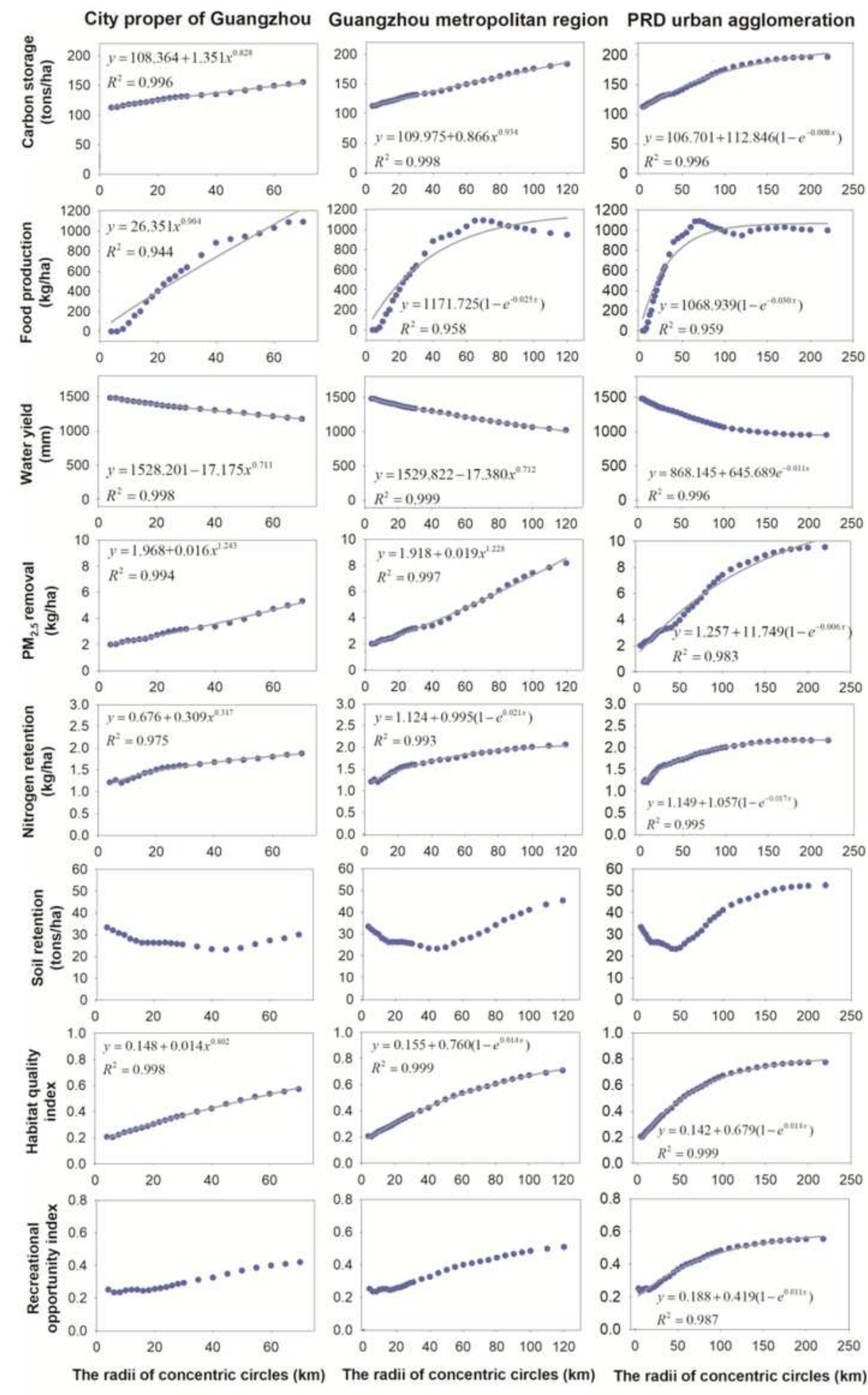

- Ecosystem service values

Regression curve

Figure 9

Scalograms of multiple ecosystem service indicators with respect to increasing concentric circle radii at various urban hierarchical levels: the city proper of Guangzhou, Guangzhou metropolitan region, and the 
Pearl River Delta (PRD). For all regression curves and equations, the significance level $P$ values $<0.001$.

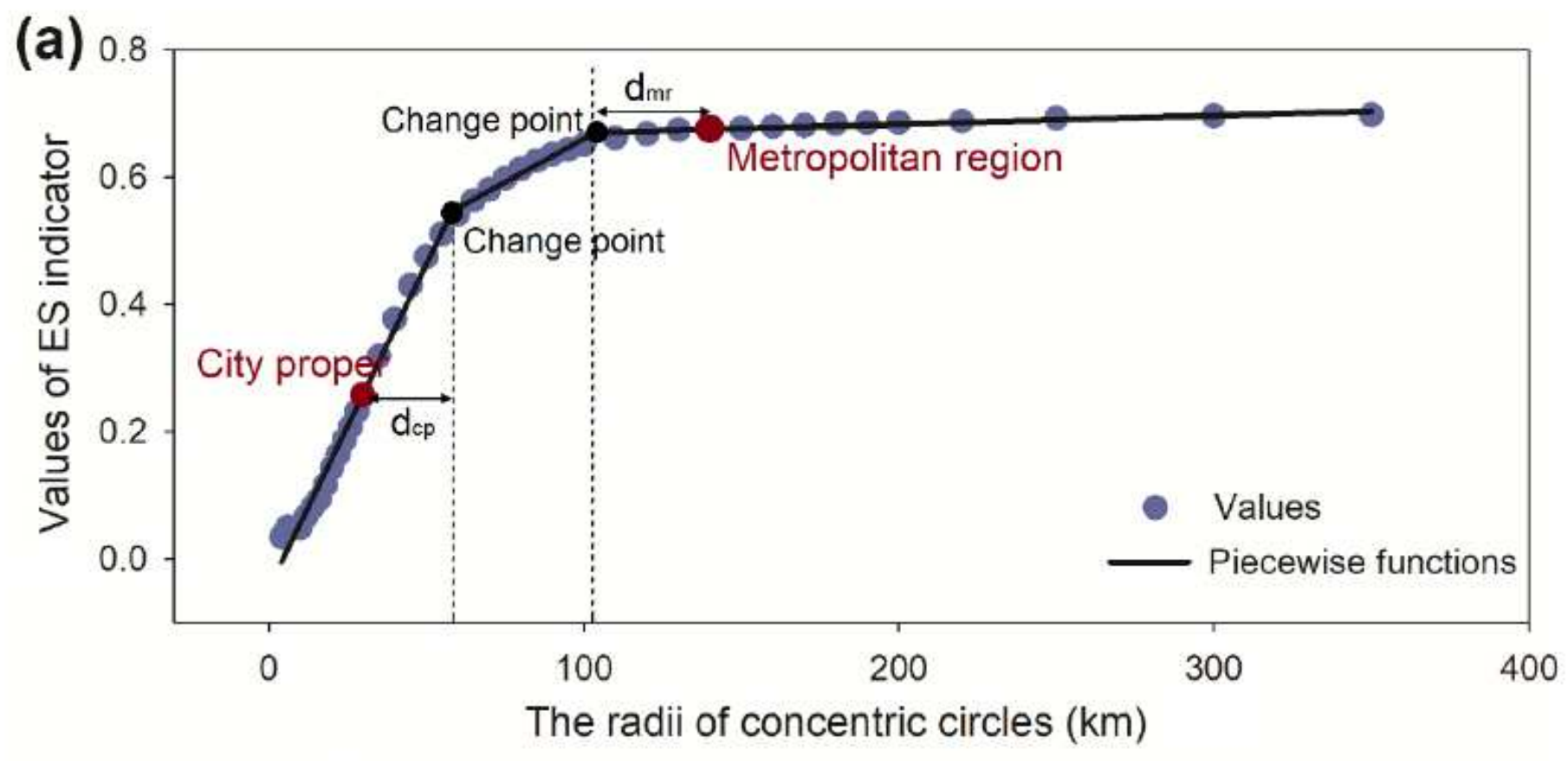

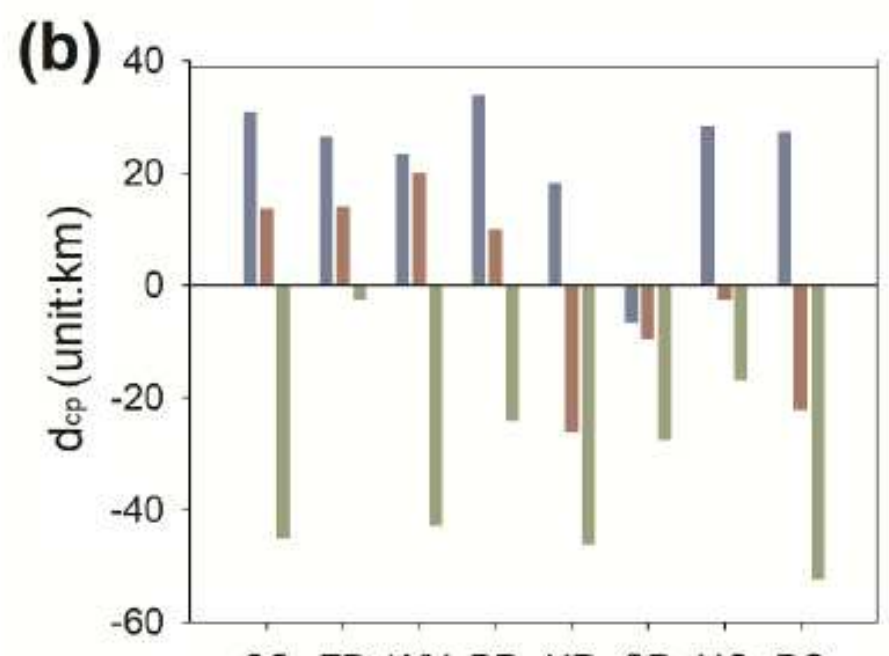

CS FP WY PR NR SR HQ RS ES indicators

Beijing-Tianjin-Hebei

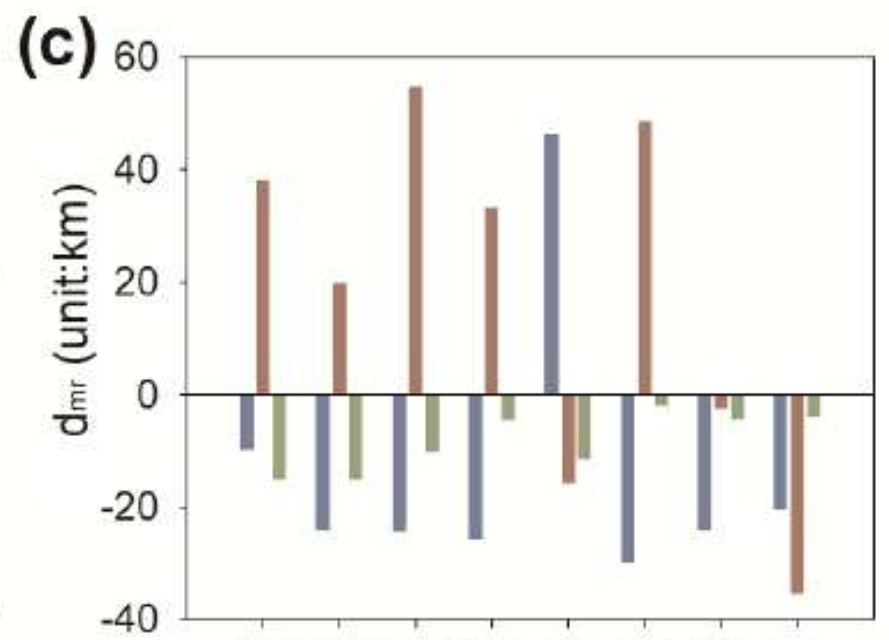

CS FP WY PR NR SR HQ RS ES indicators

Yangtze River Delta

\section{Figure 10}

(a) Example of a scalogram for ecosystem service (ES) change points versus the administrative boundary points. The solid black dots represent the turning points for the ES change rates; the solid red dots represent the administrative boundary points. The "dcp" represents the distance between the first change point of ES scaling relations and the administrative boundary of the city proper; the "dmr" represents the distance between the second change point of ES scaling relations and the administrative boundary of the metropolitan region. Distance was calculated by the change point value minus the administrative boundary value. (b) The "dcp" for multiple ESs in Beijing Tianjin Hebei (BTH), Yangtze River Delta (YRD), and Pearl River Delta (PRD) urban agglomerations. CS = carbon storage; FP = food 
production; $\mathrm{WY}=$ water yield; $\mathrm{PR}=\mathrm{PM} 2.5$ removal; $\mathrm{NR}$ = nitrogen retention; $\mathrm{SR}=$ soil retention; $\mathrm{HQ}=$ habitat quality; RS = recreational opportunity. (c) The "dmr" for multiple ESs in BTH, YRD, and PRD urban agglomerations.

\section{Supplementary Files}

This is a list of supplementary files associated with this preprint. Click to download.

- SupplementaryInformationSI.docx

- Supplementaryfigures.docx 